\title{
La Ciudad Universitaria de Madrid y las ideologías políticas: un patrimonio con noventa años de historia
}

The Ciudad Universitaria in Madrid and the politic ideologies:

A 90 years old built heritage

Dra. Pilar Chías Navarro

Catedrática y Directora de la Escuela de Arquitectura de la Universidad de Alcalá, España.

$\triangle$ pilar.chias@uah.es [orcid.org/0000-0001-6686-8820]

\begin{abstract}
RESUMEN
La influencia que tiene la ideología en la arquitectura es un hecho probado y, en consecuencia, ésta se refleja claramente en los conjuntos universitarios de todas las épocas. La Ciudad Universitaria de Madrid constituye un conjunto singular entre los campus construidos a lo largo del siglo XX, pues ha soportado una monarquía del "Antiguo Régimen”, una república, la dictadura franquista y una monarquía parlamentaria. Cada una dejó su huella materializada en sus edificios y monumentos, en sus usos, y en el diseño de sus jardines y sus espacios libres y deportivos. Pero también en la educación universitaria que en ella se impartió casi ininterrumpidamente desde 1935.
\end{abstract}

PALABRAS CLAVE: Ciudades Universitarias, España, siglo XX.

\section{ABSTRACT}

Ideology exerts considerable influence on architecture, as it is clearly evidenced in the university cities of all times. The Ciudad Universitaria in Madrid forms a unique complex among the campuses built along the $20^{\text {th }}$ century, because it should face an 'ancient régime' monarchy, a republic, Franco's dictatorship and a constitutional monarchy. Each one left its mark on the buildings and monuments, on its uses, on its gardens and open air sport areas. Traces that can still be tracked as essential components of the education provided almost without interruption since 1935.

KEY WORDS: University cities, Spain, $20^{\text {th }}$ century. 


\section{INTRODUCCIÓN Y PRECEDENTES}

La ideología política influye en múltiples ámbitos de la vida de los ciudadanos, de entre los que la educación y la formación de los jóvenes resultan particularmente importantes por sus repercusiones en el futuro.

La arquitectura y la ciudad pueden llegar a reflejar claramente las intenciones políticas de quienes las impulsaron, convirtiéndose en la materialización de un ideario. En este sentido, la construcción de una universidad es especialmente sensible a estos efectos.

El caso de la Ciudad Universitaria de Madrid se revela como un ejemplo de estudio particularmente singular debido a que se llevó a cabo a lo largo de casi un siglo y a que durante este dilatado periodo hubo de soportar dos monarquías -una vinculada al ideario del Antiguo Régimen y otra, la actual, parlamentaria-, la breve Segunda República y una larga dictadura de cuarenta años.

Factores extraños a un proyecto universitario estrictamente enfocado al conocimiento y a la investigación -como la influencia de una educación laica o religiosa- han tenido un peso variable que se ha traducido, por ejemplo, en el diseño de diferentes espacios para el culto; asimismo, la voluntad propagandística de la dictadura llevó a imponer unos símbolos que aún perduran, afortunadamente ya desprovistos de su carga ideológica para las nuevas generaciones.

Estudiar cómo el proyecto evolucionó vinculado a los avatares políticos de la España del siglo XX, es el objetivo del presente artículo.

Para ello se ha desarrollado un método de investigación basado en evidencias y siguiendo un orden cronológico, que pone de manifiesto en cada periodo las relaciones entre arquitectura, proyecto urbano e ideología, analizando sus consecuencias en cada momento histórico y, finalmente, sus repercusiones en el conjunto universitario actual.

Los precedentes son esencialmente testimonios contemporáneos a los distintos periodos de construcción, como se puede comprobar en las referencias que se adjuntan. A López Otero se deben las reflexiones directas de mayor interés y con mayor carga ideológica, debido a su condición de arquitecto director de las obras antes y después de la Guerra Civil; en este sentido son también muy reveladoras las decisiones del ministro franquista Ibáñez Martín. En el ámbito de la crítica arquitectónica, destacan las contribuciones de Bonet Correa, Bohigas, Solá-Morales y Tusell y Queipo de Llano. Los principales estudios que se han publicado sobre el tema concreto del desarrollo arquitectónico y urbanístico de la Ciudad Universitaria se deben a la autora.

\section{CONTEXTO}

El reinado de Alfonso XIII (1902-1931) se vio lastrado por siglos de decadencia de España. La tardía industrialización, unas malas comunicaciones interiores seculares, los 
servicios desorganizados y mal atendidos, las constantes guerras -varias de ellas de carácter interno-, y el cúmulo de errores políticos y tácticos habían conducido al país a una situación de retraso y pobreza frente a Europa.

Por otra parte, la conciencia de la pérdida de los últimos restos del Imperio tenía al país conmocionado. El propio Rey reconocería en su Diario a principios de enero de 1902: "[...] yo me encuentro el país quebrantado por nuestras pasadas guerras, que anhela por un alguien que lo saque de esa situación [...]" (Tusell \& Queipo de Llano, 2001, p. 248). Pues aunque el país era capaz de producir científicos, profesionales, pensadores, literatos y artistas de altísimo nivel -como Santiago Ramón y Cajal, Leonardo Torres Quevedo, José Ortega y Gasset, Miguel de Unamuno o Joaquín Sorolla, por citar sólo algunos-, las carencias y deficiencias estructurales eran evidentes en muchos aspectos, y a ellas no eran ajenos los ámbitos asistencial y docente.

Para paliar estas deficiencias el rey decidió, como veremos, abordar la magna empresa de la Ciudad Universitaria, con un doble objetivo: en primer lugar, de recuperar una tradición universitaria que había sido importante para España y para Europa desde la Edad Media y que se continuó en los países de Hispanoamérica a partir del siglo XVI con la fundación de universidades en suelo americano. Y en segundo lugar, con la intención de recuperar los vínculos perdidos con los países que antaño habían sido súbditos de la corona española.

\section{La tradición universitaria española}

Las ciudades universitarias históricas españolas como Salamanca, Santiago, Palencia, Sevilla, Valencia o Alcalá, habían conformado un modelo de Universidad fragmentada cuyos edificios, en muchos casos de gran valor patrimonial, se hallaban diseminados por el casco urbano ocupando una parte importante de su suelo (Fig. 1).

En el caso concreto de Alcalá, una de las consecuencias de las desamortizaciones de los bienes eclesiásticos en 1836 fue el abandono de los colegios y de los usos docentes, que se trasladaron a la cercana ciudad de Madrid bajo el nombre de Universidad Central. En ella ocuparon una serie de viejos caserones que distaban mucho de adaptarse a las nuevas necesidades que se estaban planteando en Europa y Estados Unidos, y que presentaban un diseño anticuado y escasa capacidad de adaptación a los nuevos criterios y avances pedagógicos.

En estos edificios destinados a la docencia, las aulas y otras dependencias se solían organizar en torno a patios, tendiendo a reproducir las mismas simetrías y distribuciones propias de la tipología tradicional del palacio (Castillo Oreja, 1982, pp. 727-748). En consecuencia, y salvo en contadas excepciones como los anfiteatros de cirugía, no existía una tipología de específica para las aulas y pocas diferencias se podían encontrar entre los salones de un palacete y un aula de filosofía en lo referente al estilo arquitectónico y el ornamento, al diseño de huecos, y a la elección de los materiales y acabados, o a los volúmenes y al tipo de 


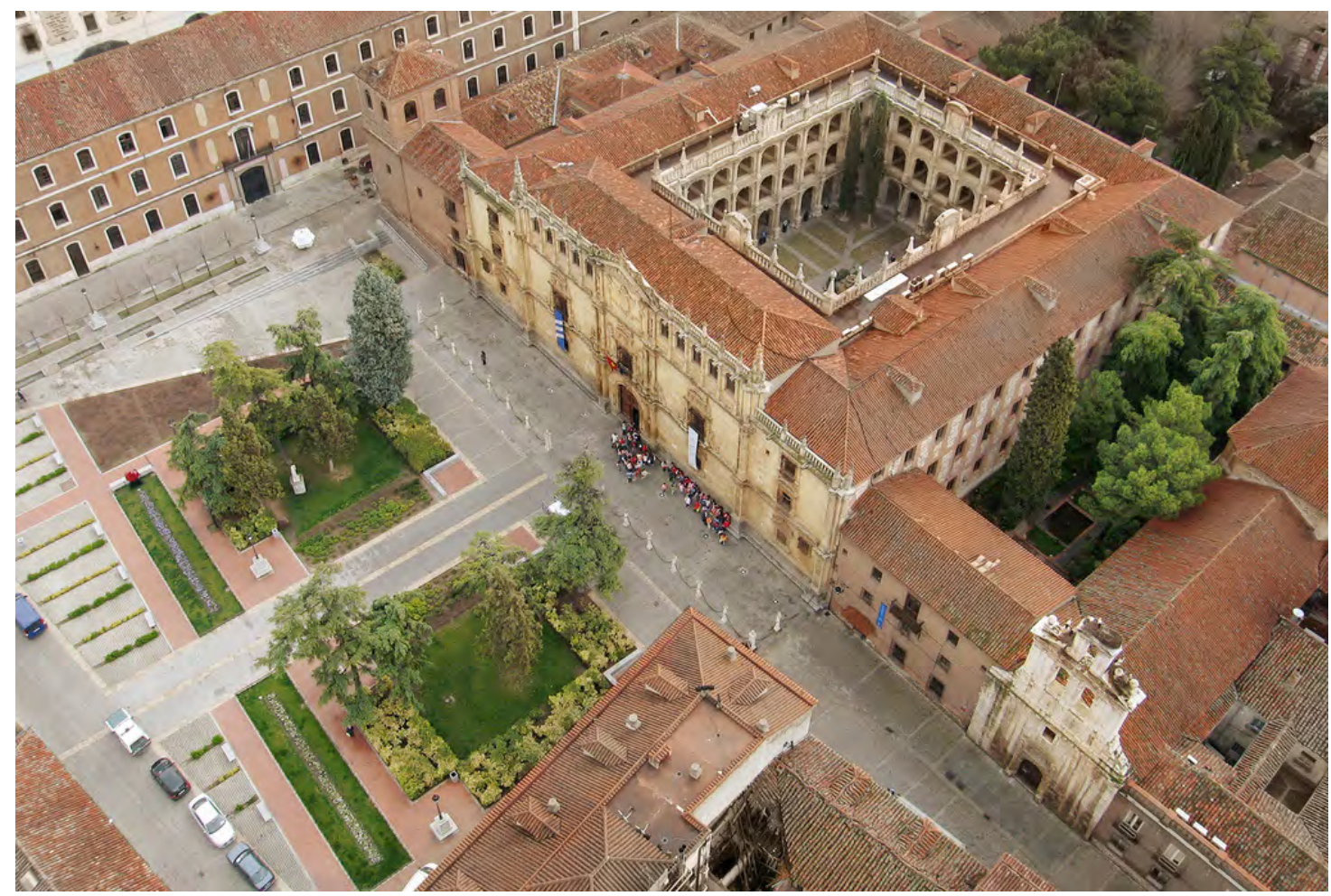

Fig. 1. Vista aérea de los Colegios de San Ildefonso y de San Pedro y San Pablo, Universidad de Alcalá, España. (Fuente: Archivo Fotográfico de la Universidad de Alcalá).

construcción.

Una falta de adecuación que se hacía aún más patente en los edificios destinados a ejercer la asistencia y las disciplinas médicas. A la tradicional carencia y fragmentación de las instalaciones asistenciales que existía en Madrid, se unieron circunstancias adicionales que pusieron de manifiesto su insuficiencia para hacer frente a contingencias como la avalancha de heridos procedentes de la Guerra de Marruecos que llegó a Madrid durante el verano de 1921.

Para paliar esta carencia se construyó una serie de edificios provisionales y eclécticos en el borde del perímetro edificado de la ciudad. Entre ellos se encontraban los pabellones prefabricados de bajo coste tipo Docker que, con una imagen ecléctica, se ubicaron en el límite con la finca real de La Moncloa, al noroeste de Madrid, sobre el cerro que años después iba a ocupar el Hospital Clínico (Fig. 2).

La elección del lugar no fue casual, pues se aprovechó la proximidad de un pequeño núcleo de construcciones benéfico-asistenciales que ya prefiguraba una "zona universitaria” en el planeamiento urbano contemporáneo de Madrid, como figura en el plano de urbanización del extrarradio elaborado por el ingeniero Pedro Núñez Granés (Fig. 3).

Y aunque no cabe duda de que el prestigio y la imagen de la monarquía jugaron un importante papel en la renovación universitaria, los móviles reales fueron diversos, como 

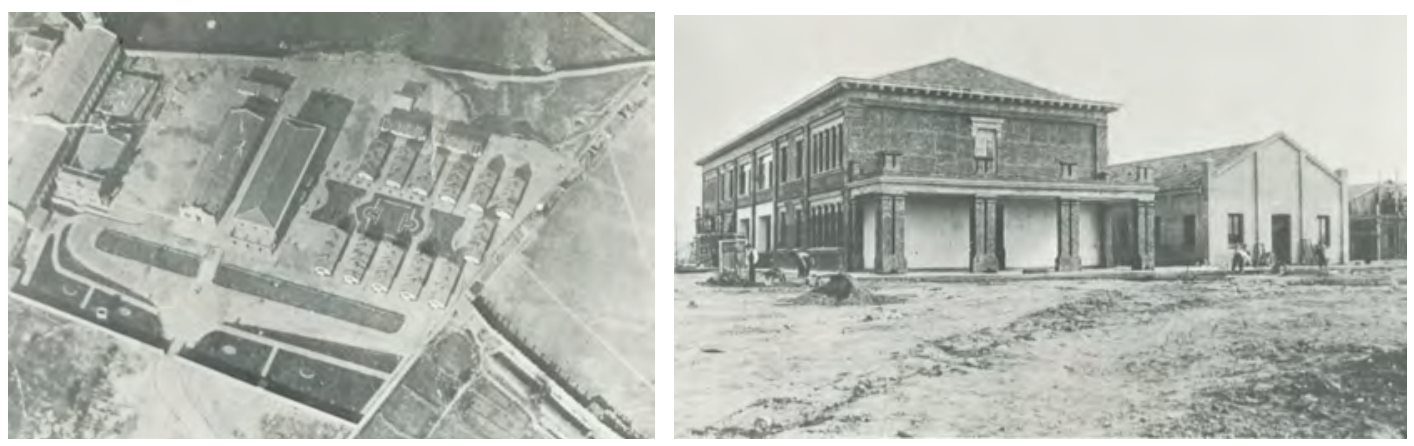

Fig. 2. Los quince pabellones Docker en 1929 que junto a otros edificios no provisionales se construyeron en los terrenos de la Ciudad Universitaria. Por su doble función docente y asistencial constituyeron el germen de la Facultad de Medicina. (Fuente: Chías, 1986, p. 68).

explicó el propio Alfonso XIII en fecha tan temprana como 1924 a un grupo de asistentes al Congreso Nacional de Arquitectos en Santander, al hablar de lo que pensaba que iba a ser "la obra de su reinado":

Los edificios universitarios son viejos e inadecuados comparados con los que he visto en otros países. Me han dicho que ustedes, los arquitectos, tienen una escuela impropia de su misión [...] Yo he pensado en la necesidad de emprender la construcción de los edificios de una gran universidad que no fuera solamente nacional sino hispano-americana, brindando a aquellos estudiantes que hoy se van a París y a Norteamérica la posibilidad de una formación científica y cultural netamente española, y para lo cual habría, naturalmente, que mejorar los métodos y ampliar las dotaciones para material y profesorado. Ya sé que todo esto es económicamente difícil para nuestro Estado, pero puede realizarse con el tiempo según un plan bien organizado [...] (Chías, 1986, p. 29).

La materialización de este "plan” parecía ser inminente entre 1919 y 1929, con evidencias como la creación de dos comisiones para estudiar el emplazamiento y definir un programa, la redacción de toda una serie de reales órdenes, planos e informes, e incluso la presentación en 1923 de un proyecto de ley en las Cortes "que alcanzó la aprobación del Senado, pero que precisamente en la sesión del Congreso donde se esperaba su refrendo fue promovida la crisis que hizo caer aquella situación conservadora y dejó el proyecto en espera de mejor ocasión" (Luque, 1931, p. 12).

Sin embargo, el proyecto no decayó y fue apoyado desde diversos sectores de la opinión pública, ansiosos de participar en él con propuestas vinculadas a la reforma de las enseñanzas, las posibilidades de financiación y gestión, o la elección del emplazamiento -que llegó a contemplar la vuelta de la Universidad a Alcalá- y la tipología edificatoria (Chías, 1986, pp. 34-35). La ocasión de llevar a cabo el plan se presentó el 17 de mayo de 1927 coincidiendo con el XXV aniversario de la jura de la Constitución por el rey. Fue entonces cuando se creó la Junta de la Ciudad Universitaria, que, con carácter autónomo y autosuficiente habría de 
facilitar el rápido desarrollo del proyecto -aunque con una visión poco plural o vanguardista.

Como es natural, en la Junta reinaban criterios tradicionalistas. No se podía hablar allí de importaciones funcionales, sino de trasladar a las nuevas construcciones universitarias las castizas y graciosas fachadas de Alcalá, ni aun haciendo patente la incongruencia, el anacronismo de aquellas galanas y profusas menudencias cubriendo la austeridad y frío utilitarismo de las clínicas y laboratorios, ya que la Universidad de hoy es bien distinta en su organización, funcionamiento y finalidad, de las del siglo XVII [...] Las formas tradicionales o los híbridos y estériles modernismos de importación francesa o alemana, o aun italiana, seguían siendo preferidos, y lo poco que de las nuevas corrientes se conocía, por otro lado mezquinas y mal interpretadas, sólo lograba una fuerte y airada oposición pública, con más virulencia en las capas sociales elevadas, incluso en las intelectuales [...] (López Otero, 1959, p. 41).

La Junta se constituyó en varias Comisiones Especiales cuyo cometido era gestionar con rapidez varios aspectos parciales del proyecto como la adquisición de terrenos, la urbanización y definición de las infraestructuras y el viario principal, la convocatoria de un concurso de proyectos para la futura Ciudad Universitaria -que no se llevó a cabo- y la búsqueda de financiación, entre otras.

Por otra parte, los contactos establecidos por sus miembros en Estados Unidos habían logrado interesar a instituciones como Rockefeller -que había convocado un concurso para la realización de un Instituto de Física y Química en la madrileña calle Serrano (El Concurso, 1932, s.p.)- o Carnegie coincidiendo con la llegada a España de las primeras multinacionales. La Ciudad Universitaria se benefició de su ayuda, pero a cambio de firmar convenios que compensaron tal ayuda -por ejemplo, el mobiliario de los futuros laboratorios se realizó en España según modelos y patentes norteamericanos.

\section{EL ÁMBITO ESPACIAL: CARACTERÍSTICAS DE LA FINCA DE LA MONCLOA}

La finca de La Moncloa fue el emplazamiento elegido para construir la Ciudad Universitaria aprovechando aquel primer núcleo docente-asistencial que había ido surgiendo en sus bordes desde la segunda mitad del siglo XIX (Fig. 3).

La finca se situaba al noroeste de la periferia madrileña, en la margen izquierda del río Manzanares, y salvo pequeñas construcciones, estaba prácticamente desocupada.

Los terrenos habían pasado a ser propiedad de la Corona en dos fases consecutivas: en 1772, cuando la Princesa Pío le había vendido el palacio, jardines y huertas de la Florida, y en 1795, cuando el Duque de Alcudia había cedido la Huerta de la Moncloa, antes conocida como Fuentes del Sol (Winthuysen, 1930).

Tras la posterior cesión de la finca al Estado en 1886, a raíz de la enajenación de muchos de los bienes del patrimonio real, sus usos se popularizaron, especialmente en 

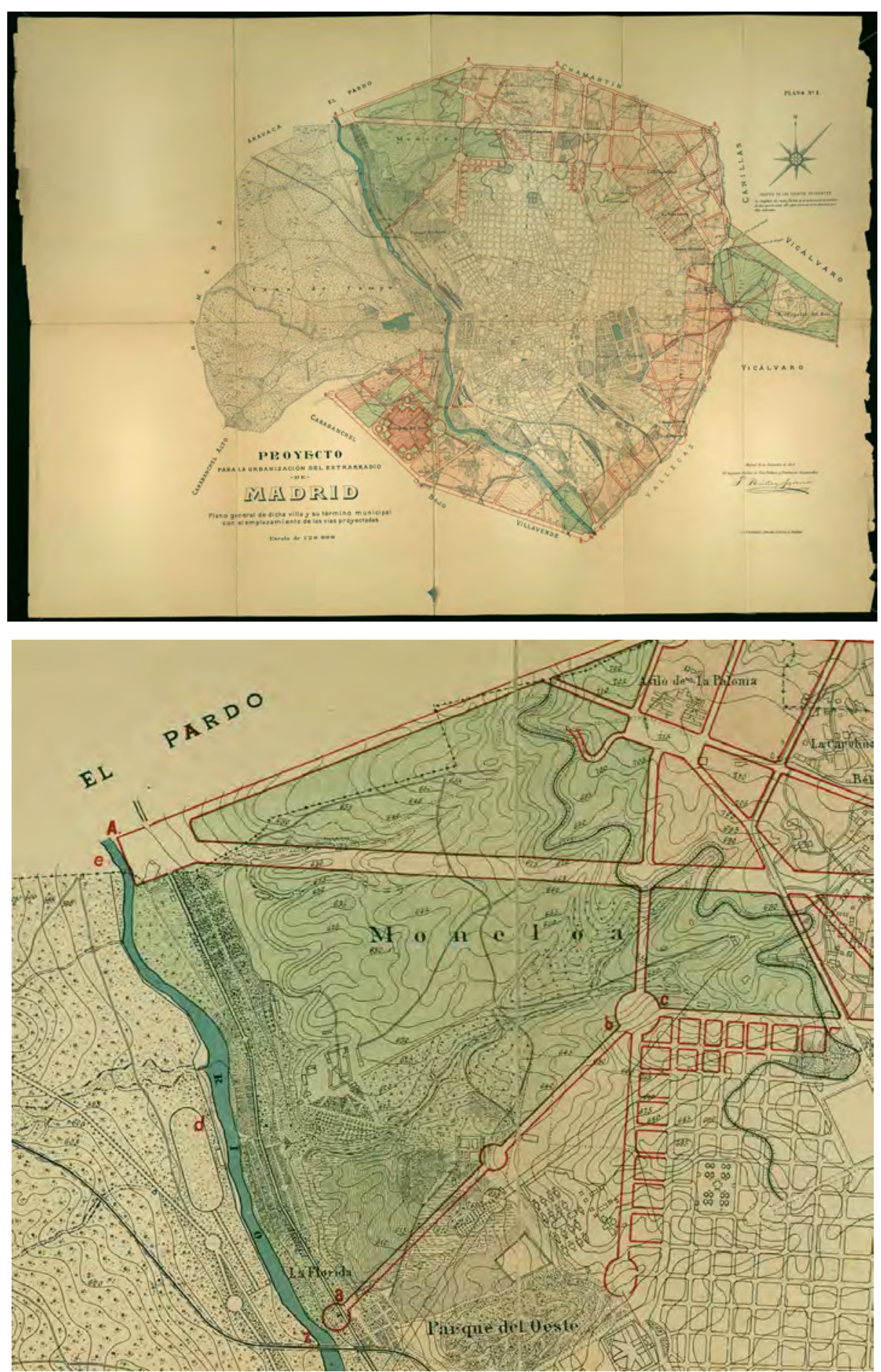

Fig. 3. Los terrenos que posteriormente ocuparía la Ciudad Universitaria, representados en el Proyecto de Urbanización del Extrarradio redactado por el ingeniero militar Pedro Núñez Granés en 1910. Arriba, el plano general del proyecto. Abajo, detalle de la zona del Real Sitio de la Florida mostrando los usos principales. (Fuente: Biblioteca Digital de la Comunidad de Madrid). 
las zonas de borde, donde empezaron a proliferar establecimientos para el ocio junto a los asistenciales. Sin embargo, los terrenos iniciales pronto resultaron insuficientes para desarrollar un proyecto que cada vez iba cobrando una mayor envergadura, de modo que de las quince hectáreas de la primera finca se pasó, mediante sucesivas adquisiciones, a treinta y cinco definitivas a las que se habían ido incorporando otros usos ajenos a la Universidad como el Instituto de Higiene Alfonso XIII, la Casa de Velázquez, la Escuela de Ingenieros Agrónomos o el Instituto Príncipe de Asturias.

\section{EL PRIMER PROYECTO PARA LA CIUDAD UNIVERSITARIA DE MADRID}

Antes y entonces [1928], los arquitectos construíamos, ya en las ideas de un historicismo ecléctico, con manifestaciones locales o regionales [...] ya en cualquiera de aquellas manifestaciones de modernismo, efímeras por lo mal orientadas, con que se pretendía conseguir la otra arquitectura, que reemplazase, como expresión de los nuevos tiempos a las adaptaciones, más o menos fieles, de los estilos históricos del siglo anterior [...] (López Otero, 1959, cit. en Chías, 1986, p. 41).

Así manifestaba López Otero las limitaciones que la mayoría de los arquitectos tenían entonces para diseñar los edificios de acuerdo con las tendencias vanguardistas que venían de Europa, y que les obligaban a supeditar sus proyectos al gusto burgués imperante entre la burguesía y la aristocracia españolas.

Sin embargo, una oportuna invitación de la Fundación Rockefeller para realizar un viaje a los principales centros universitarios en Europa y Norteamérica cambió súbitamente el ritmo y las directrices del proyecto de urbanización conjunto, a la vez que abrió las perspectivas de los arquitectos a la realización de nuevos diseños arquitectónicos.

Al regresar en noviembre de 1927, López Otero publicó unas interesantes reflexiones en el Diario $A B C$ sobre los contenidos de su diario de viaje: "Lo más perfecto lo encontramos en Norteamérica por constituir verdaderas ciudades, no sólo universidades o residencias aisladas" (López Otero, 1927).

Como una primera consecuencia, en los primeros días de diciembre la Junta resolvió dar un giro radical a los planteamientos y ampliar el modesto programa inicial de construcciones asistenciales y docente; asimismo la arquitectura de los distintos edificios se modernizó, perdiéndose la mayoría de los vínculos con el eclecticismo historicista imperante (Chías, 1986, pp. 51-53).

Los nuevos criterios que guiaron el esquema principal de urbanización del conjunto se basaron en la creación de una universidad jardín que reinventaba el concepto de Campus norteamericano:

[...] Agrupar bajo un plan magnífico y completo de modernas construcciones 
en un bello y amplio parque, con todas las comodidades y todo el detalle moderno, las distintas escuelas y facultades que hoy integran en todo el mundo la completa preparación científica, literaria y artística de las juventudes, dejando el anticuado sistema del edificio único universitario para trocarlo por el de edificios independientes para las diversas ramas del saber; procurar en este recinto mismo alojamiento cómodo, comida abundante, barata y sana, y honestas recreaciones a los estudiantes que cursen en estas escuelas sus estudios; unir a la enseñanza y al cómodo y agradable hospedaje, la práctica de los deportes, complemento indispensable de la moderna educación, y la preparación militar indirecta, terrible necesidad social que aún no puede eliminarse de los usos ni de la vida; y todo esto en lugares apropiados, situados dentro del propio recinto universitario: crear un sistema de residencias clasificadas para los estudiantes de los diversos países, a fin de que los pueblos y las razas convivan independientes dentro del trabajo común; y unir a todo esto un sistema económico de becas y pensiones que asegure el intercambio escolar entre España y los países americanos. Tal es la organización fundamental y sintética de la Ciudad Universitaria española (Junta de Obras, 1930).

Un primer problema al que se enfrentó el nuevo campus fue precisamente el de la reinvención de los modelos anglosajones, sin contar con el adecuado soporte económico -ausencia de mecenazgo, inexistencia de un tejido empresarial vinculado a la investigaciónni social, puesto que la gran mayoría de los habitantes del país no tenía entonces capacidad material -había un 25\% de analfabetismo- de acceder a unos estudios universitarios centralizados además en Madrid.

No obstante, se diseñó un primer proyecto de conjunto, muy ambicioso, monumental, en una clara tradición Beaux Arts y poco realista, estructurado por ámbitos científicos (Fig. 4).

El proyecto suscitó numerosas críticas, que afectaron tanto a la reforma de la enseñanza -abogando por el necesario complemento de la formación universitaria con las artes y oficios, y eliminando el sesgo elitista del planteamiento-, como a la futura ubicación -pues la finca de La Moncloa quedaba muy alejada de Madrid y carecía de infraestructuras-, a la financiación, e incluso a la tipología arquitectónica a adoptar -el volumen único de "gran estilo arquitectónico" o la dispersión en pabellones.

Insensible a las críticas, el proyecto se comenzó a construir.

En un primer grupo de construcciones necesarias se incluyeron las facultades de Medicina, Farmacia y Ciencias, el Hospital Clínico con una capacidad de mil quinientas camas, las facultades de Filosofía y Letras y Derecho, la gran Biblioteca universitaria, las residencias de estudiantes y profesores, y la zona de Deportes, además de los edificios de representación del gobierno y servicios de la Universidad, y una Escuela Militar Universitaria.

En una segunda fase se construirían las escuelas de Bellas Artes, Arquitectura y Especial de Pintura, Escultura y Grabado, a la vez que se ampliaría la ya existente Escuela de Ingenieros 


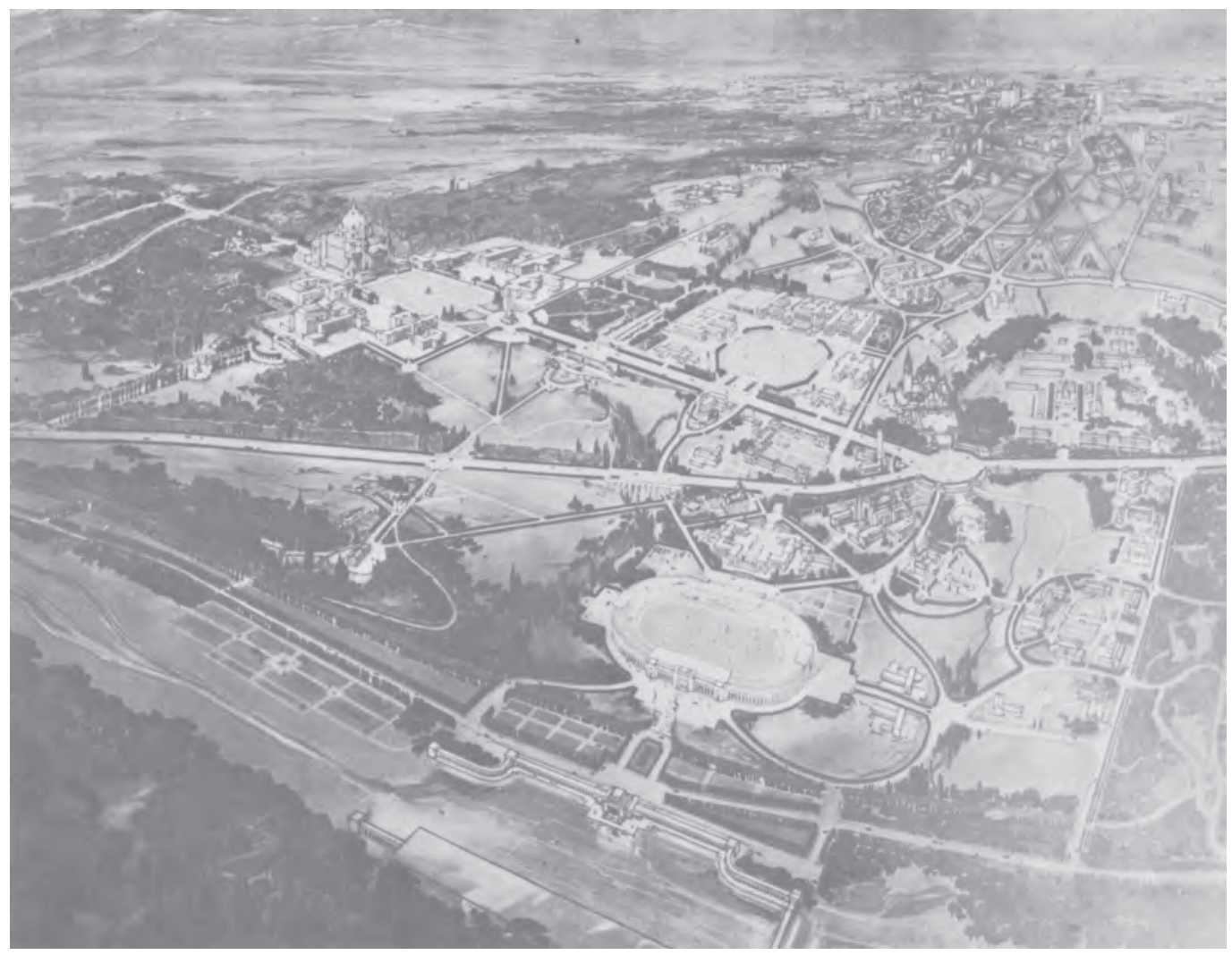

Fig. 4. Junta de Obras de la Ciudad Universitaria, diciembre de 1928: Perspectiva ideal de la Ciudad Universitaria. La nueva universidad-jardín debía atenuar la densidad de la capital y constituir un filtro entre ésta y el campo. (Fuente: Chías, 1986, p. 78).

Agrónomos.

Por último, en una tercera fase se abordaría la construcción de las escuelas de Ingenieros Industriales y de Ingenieros de Caminos, así como las Superiores de Comercio y Magisterio. Este programa no fue tampoco el definitivo, pues en la primera fase de construcción se integraron pronto la Escuela de Arquitectura y la de Odontología, que contaban con ilustres representantes en la Junta -el propio López Otero y el doctor Aguilar, dentista del rey.

\section{Los arquitectos e ingenieros de la primera ciudad universitaria}

A pesar de su trayectoria ecléctica como arquitecto, Modesto López Otero supo rodearse de varios de los mejores arquitectos españoles de la llamada Generación del 25, seleccionando a aquéllos "que tuvieran en su carrera antecedentes de trabajos similares". Siguiendo este criterio se incorporaron a su equipo los arquitectos Luis Lacasa y Miguel Sánchez Arcas, recientes ganadores del citado concurso para la Institución Rockefeller en Madrid. Los merecedores del segundo premio, Agustín Aguirre y Miguel de los Santos, también pasaron a formar parte del equipo de la oficina de proyectos. 
Este equipo de jóvenes arquitectos tenía un interés predominantemente intuitivo y formal por la Neue Sachlichkeit, que les llevaba a hacer propuestas de un funcionalismo superficial y un higienismo aparente a causa de las limitaciones del gusto antes expuestas, pero impulsaron la ruptura formal con los revivals regionalistas de la generación precedente que se había apoyado cómodamente en los gustos de la burguesía. Algunos de ellos serían después miembros activos del Grupo de Artistas y Técnicos Españoles para el Progreso de la Arquitectura Contemporánea -GATEPAC- (Chías, 2017). Otros brillantes arquitectos como Rafael Bergamín y Luis Blanco Soler realizaron colaboraciones concretas con la Oficina Técnica, al ser designados como arquitectos por parte de las diferentes instituciones que fueron poblando la Ciudad Universitaria, como la Fundación del Amo.

La nueva generación adelantó la simplificación de las formas y la supresión total de las reminiscencias historicistas, destacando los logros obtenidos en la utilización de la fábrica vista -aunque de ladrillos aplantillados.

Entre los ingenieros que se incorporaron al proyecto destacan dos de los ingenieros de caminos españoles más brillantes del siglo XX: Eduardo Torroja Miret y Carlos Fernández Casado. El primero fue recomendado a López Otero por el director de la Escuela de Ingenieros de Caminos, mientras el segundo lo hizo al servicio de la empresa constructora Huarte y Cia. Ambos alcanzarían después la fama internacional, y a ellos se deben las principales innovaciones estructurales de los edificios de la Ciudad Universitaria -esbeltos viaductos (Fig. 5), innovadoras estructuras para los anfiteatros anatómicos (Fig. 6), las estaciones del tranvía o la Central Térmica (Chías, 1986, pp. 112-127) -pionera en España que proporcionaba de forma centralizada calefacción y agua caliente a todo el recinto-, audaces luces para las aulas magnas (Fig. 7) y los salones de actos, etc.

Resulta también interesante el hecho de que estos ingenieros convirtieran la Ciudad Universitaria en un banco de pruebas para las nuevas soluciones estructurales, como demuestra el hecho de que el modelo de las famosas gaviotas del Hipódromo se construyera y probara en el Campus de Ciencias (Chías \& Abad, 2005).

Aunque el posterior advenimiento de la Segunda República en 1931 propició un cierto cambio de lenguaje arquitectónico hacia posiciones más progresistas (Bohigas, 1973), su repercusión en la Ciudad Universitaria fue muy limitada debido a que la mayoría de los proyectos habían quedado definidos en la fase anterior, a que la nueva Junta republicana compartía una animadversión similar hacia las nuevas tendencias arquitectónicas, y a que el equipo redactor no cambió de manera sustancial.

\section{EL DESARROLLO URBANÍSTICO ENTRE 1928 Y 1936}

A pesar de la declaración de intenciones de la Junta sobre la universidad jardín que debía constituir el nuevo campus universitario, hubo varios errores importantes en el planteamiento que lastraron su funcionamiento. Por ejemplo, se hizo una interpretación 


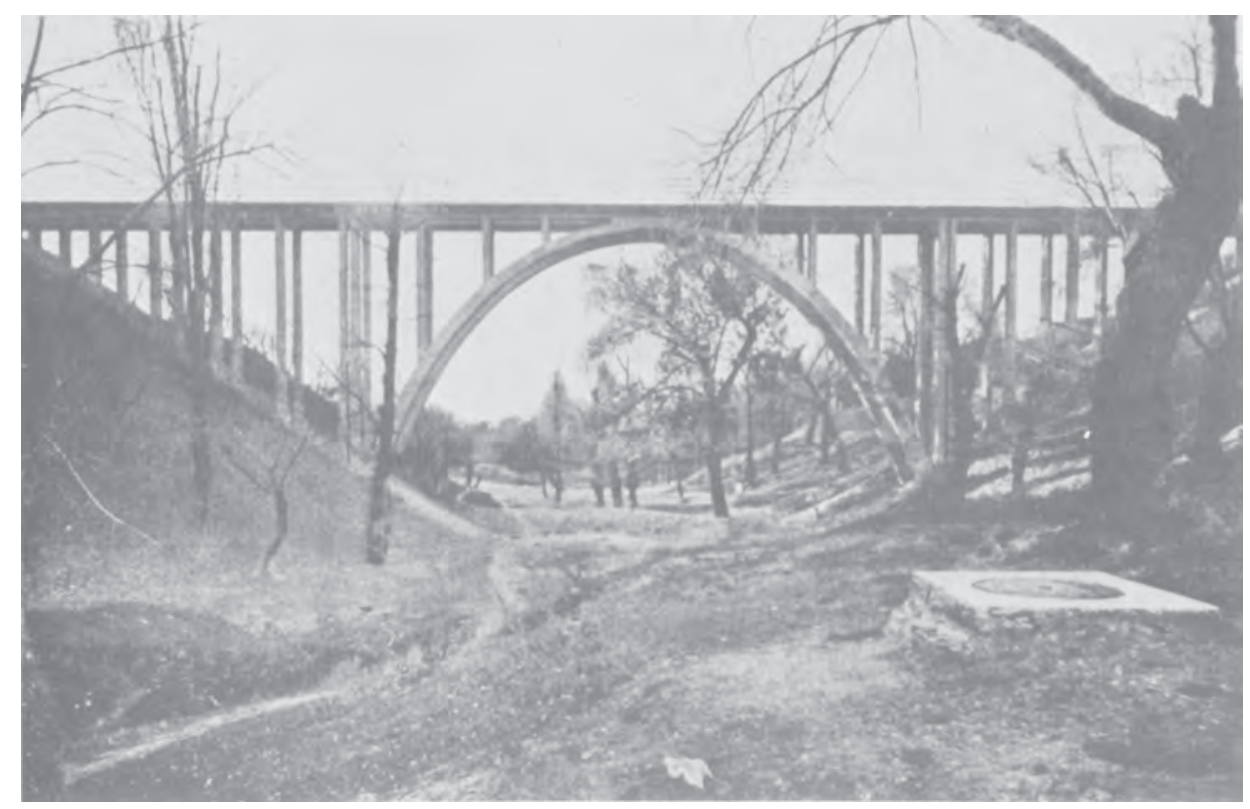

Fig. 5. Eduardo Torroja, 1934: el Viaducto del Aire, hoy enterrado. (Fuente: Chías, 1986, p. 120).

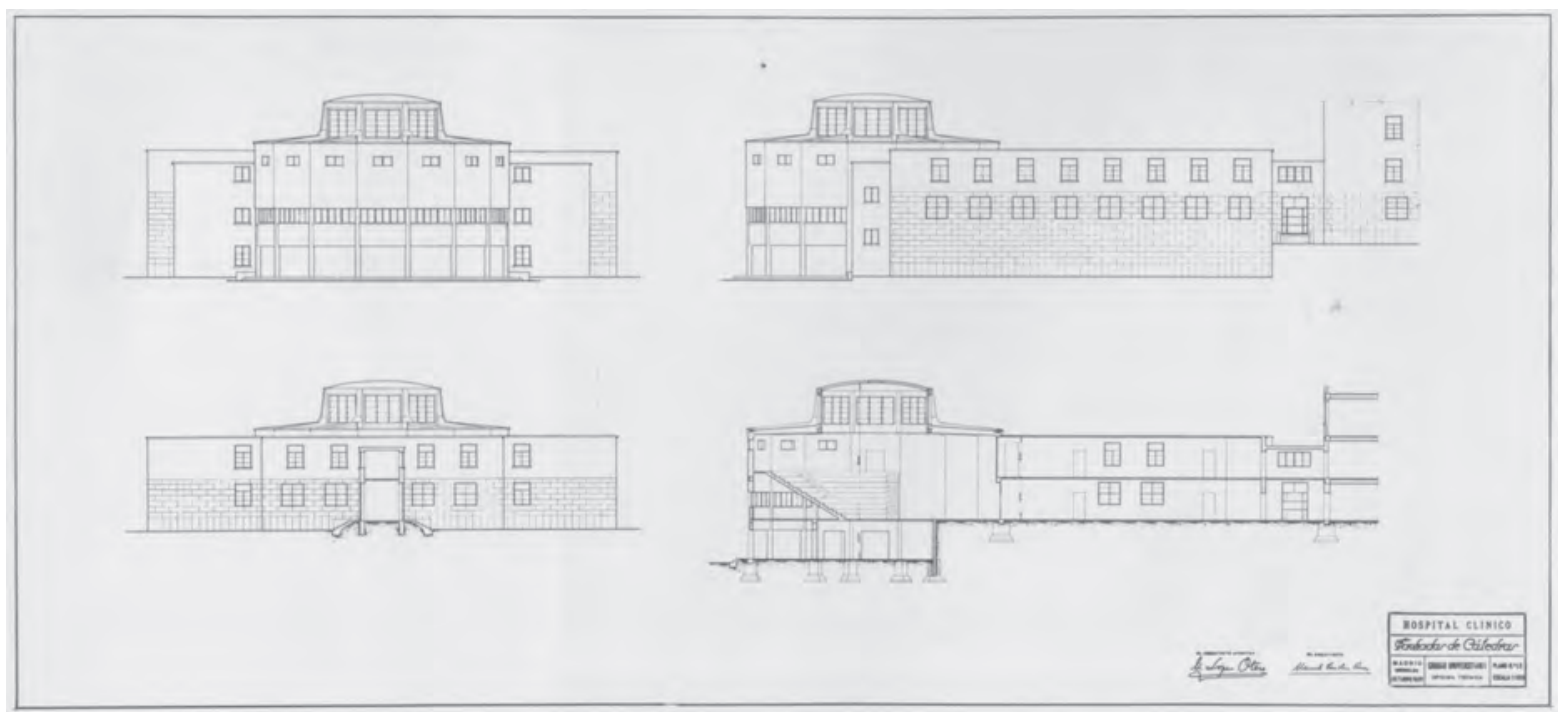

Fig. 6. Eduardo Torroja, 1934: Estructura de los nuevos anfiteatros anatómicos de la Facultad de Medicina, también conocidos como los Quirófanos de Negrín. (Fuente: Chías, 1986, p. 136).

errónea de lo que debían ser las relaciones entre los futuros usuarios y la ciudad de Madrid, pues se confió a la categoría de los edificios el establecimiento del necesario nexo en lugar de confiar tal misión a un estudio urbanístico realista.

En consecuencia, la propuesta pecó de ingenua en varios aspectos. Por ejemplo, López Otero acudía a las bondades del paseo para justificar un insuficiente transporte público, desestimando las distancias que habría que recorrer a pie, que en los casos más desfavorables superaban los $2 \mathrm{~km}$. 


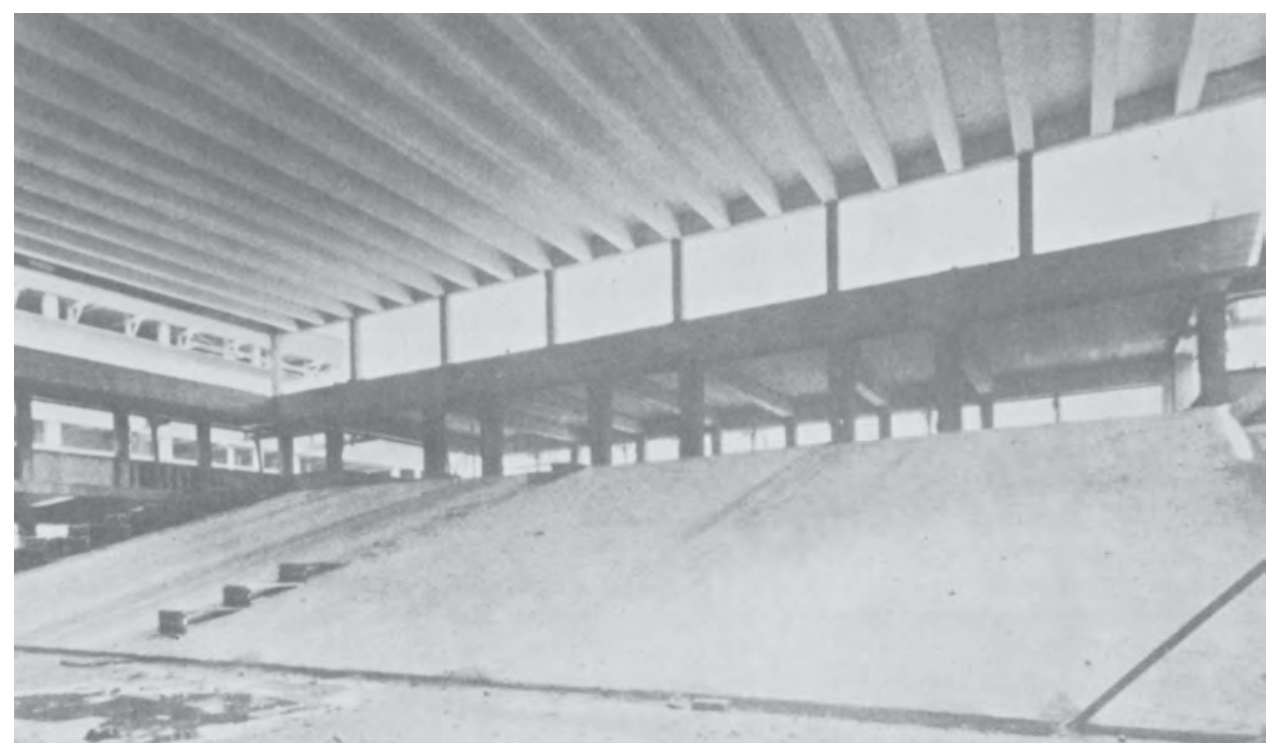

Fig. 7. Carlos Fernández Casado, 1934: Aula Magna de la Facultad de Ciencias durante su construcción. (Fuente: Chías, 1986, p. 74).

Se ha echado de menos por algunos en la Ciudad Universitaria el medio de transporte suburbano. Aparte de la cultura, el circular y acudir es un tónico necesario, dado que el clima de Madrid en los meses de curso, seco y soleado, permite deambular [...] En la Ciudad Universitaria se ha conseguido la fórmula ideal: la enseñanza en plena naturaleza -antes el estudiante debía de acudir al campo recorriendo grandes distancias; quizás en metro, que es lo peor ...- (López Otero, notas inéditas, cit. en Chías, 1986, p. 79).

Otro de los tópicos manejados fue el de la conveniencia de aislarse de Madrid.

En la Ciudad Universitaria, durante ocho horas, el estudiante debe vivir la vida de una ciudad natural: sin comercios, ni ruidos, ni aglomeraciones públicas, mal olientes. La Universidad no debe ser un producto o consecuencia de la metrópoli, y sin embargo, generalmente lo es: el mismo énfasis en los edificios, el mismo contenido urbano. La Ciudad Universitaria tiene que ser precisamente lo contrario [...] Conviene estudiar cómo la posibilidad de una selección de público toma parte en la vida cultural de la Universidad. (López Otero, notas inéditas, cit. en Chías, 1986, p. 79).

Las consecuencias de esta decisión de alejar cualquier atisbo de negocio o comercio del campus se han arrastrado hasta fechas muy recientes, pues al acabar el horario lectivo durante años el recinto quedaba vacío y sin usos alternativos.

Por otra parte, la marginación de la urbanización de la Ciudad Universitaria del 
planeamiento de Madrid tuvo el encanto de un intento falaz de aplicar las conclusiones de los CIAM, "los materiales del urbanismo que son, por este orden: sol, espacio, árboles, cemento y acero”, según López Otero.

Otro aspecto interesante fue la aplicación de criterios de zonificación según las disciplinas científicas, planteándose un esquema polinuclear según un esquema funcional racional compuesto por los siguientes grupos (Fig. 8):

I. El grupo principal, formado por el Rectorado, Paraninfo y gran Biblioteca Universitaria, flanqueado por los grupos de Filosofía y Ciencias. "Es como cabeza de la Universidad y constituye el primer fondo de toda la composición arquitectónica”.

II. “El grupo médico, integrado por las facultades de Medicina (preclínica), Farmacia y Escuela de Odontología, relacionándose aquélla directamente con el Hospital Clínico, con acceso público independiente de la zona universitaria, y bien dispuesto en relación con las vías importantes de la ciudad".

III. “Grupo de Bellas Artes, en el que se comprenderán la Escuela de Arquitectura y la de Pintura, Escultura y Grabado, además del Conservatorio de Música y Declamación en proyecto".

IV. "Grupo de residencias y deportes, posibles aquéllas para 1.500 estudiantes, inmediatas a los campos de juego [...] completos y organizados según las reglas internacionales".

V. Otros edificios "ubicados en puntos importantes" se construirían como complemento, siendo "enlazados al conjunto por el viario" (López Otero, 1941).

Como se aprecia en los planos adjuntos, en su materialización se ignoró absolutamente la topografía optando por construir extensas plataformas. Ello requirió efectuar un importante movimiento de tierras (Fig. 9) y construir un gran número de infraestructuras tales como muros de contención, cimentaciones especiales y viaductos para salvar las vaguadas.

\section{Las influencias}

Sin embargo, una observación detallada del proyecto de conjunto muestra que la propuesta se acercaba mucho a los trazados de las contemporáneas Exposiciones Universales de la época. Ignacio de Solá Morales (1980) definió así la imagen de la exposición de Barcelona de 1929, con la que podemos establecer un claro paralelismo con la Ciudad Universitaria:

Encontramos a la vez una arquitectura del poder establecido, procedente de la tradición académica y habitual de los grandes centros metropolitanos de Europa y América, que siendo en principio funcional a estos poderes muestra ya sus limitaciones e incluso irracionalidades en función de sus propios rendimientos a las necesidades de 


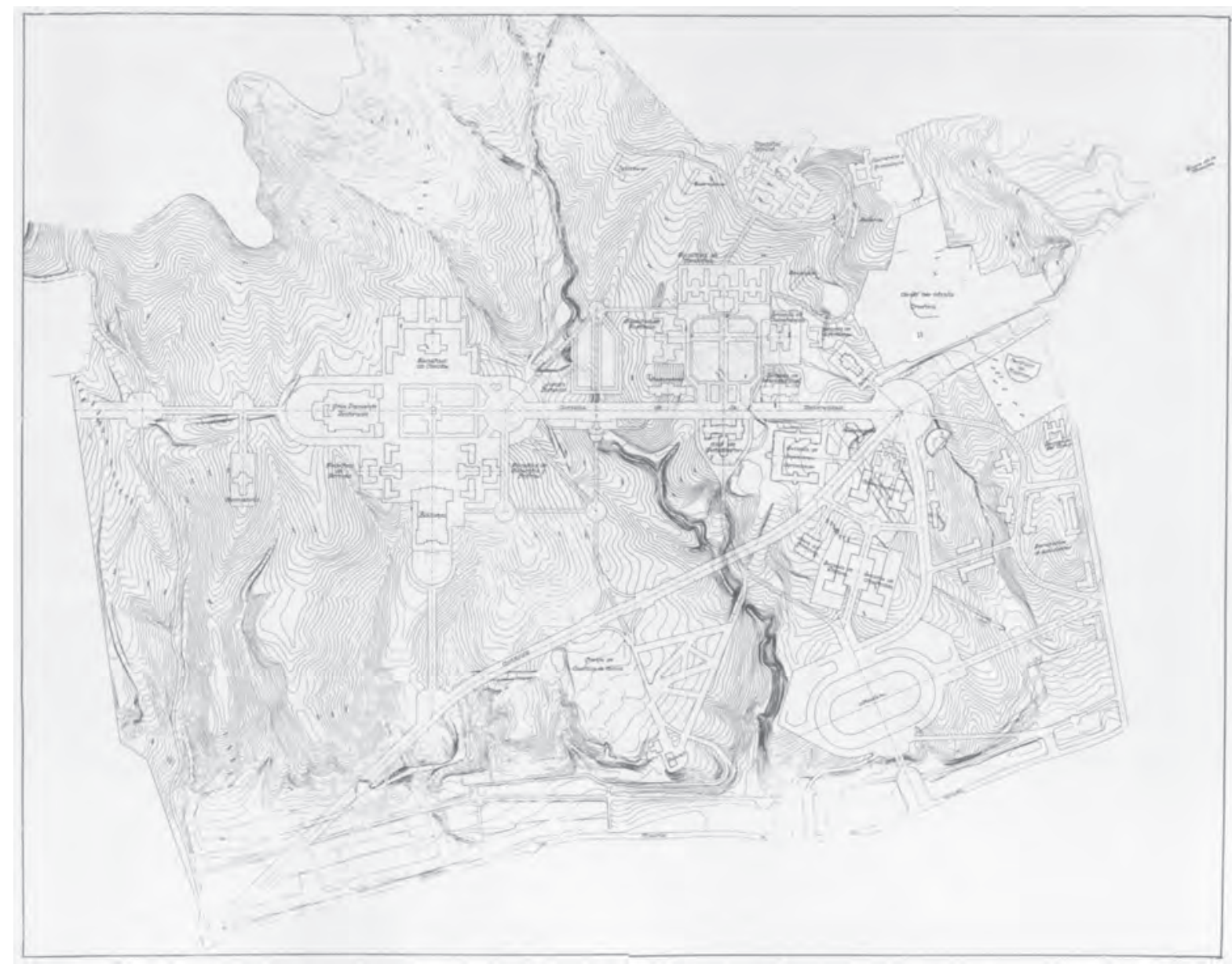

Fig. 8. Oficina de Obras, 1929: Plano del primer proyecto para la Ciudad Universitaria. (Fuente: Chías, 1986, p. 110).

las clases dominantes [...] Vemos también todo un abanico de nuevas propuestas, casi inconscientes unas, absolutamente deliberadas otras, que son en realidad prefiguración de cambios arquitectónicos que están en proceso de consolidación. Que todos estos estados de producción arquitectónica no reúnan la limpidez de las situaciones canónicas, sino que se trate de casos de contaminación, de híbridos entre viejos y nuevos modelos, serían -entre otras- las enseñanzas que la exposición de Barcelona podría ofrecer" (Solá-Morales, 1980, p. 127).

Híbrido resultó, efectivamente, el plan de conjunto, en el que cohabitaron la tradición compositiva Beaux Arts y el monumentalismo escenográfico, extremando el énfasis en los ejes y en las largas perspectivas, tan frecuentes en los grandes centros administrativos norteamericanos (Hegemann, 1925).

Otra característica importada de los campus norteamericanos fue la jerarquización del viario, acertada en su planteamiento pero desbordada posteriormente al incorporarse 


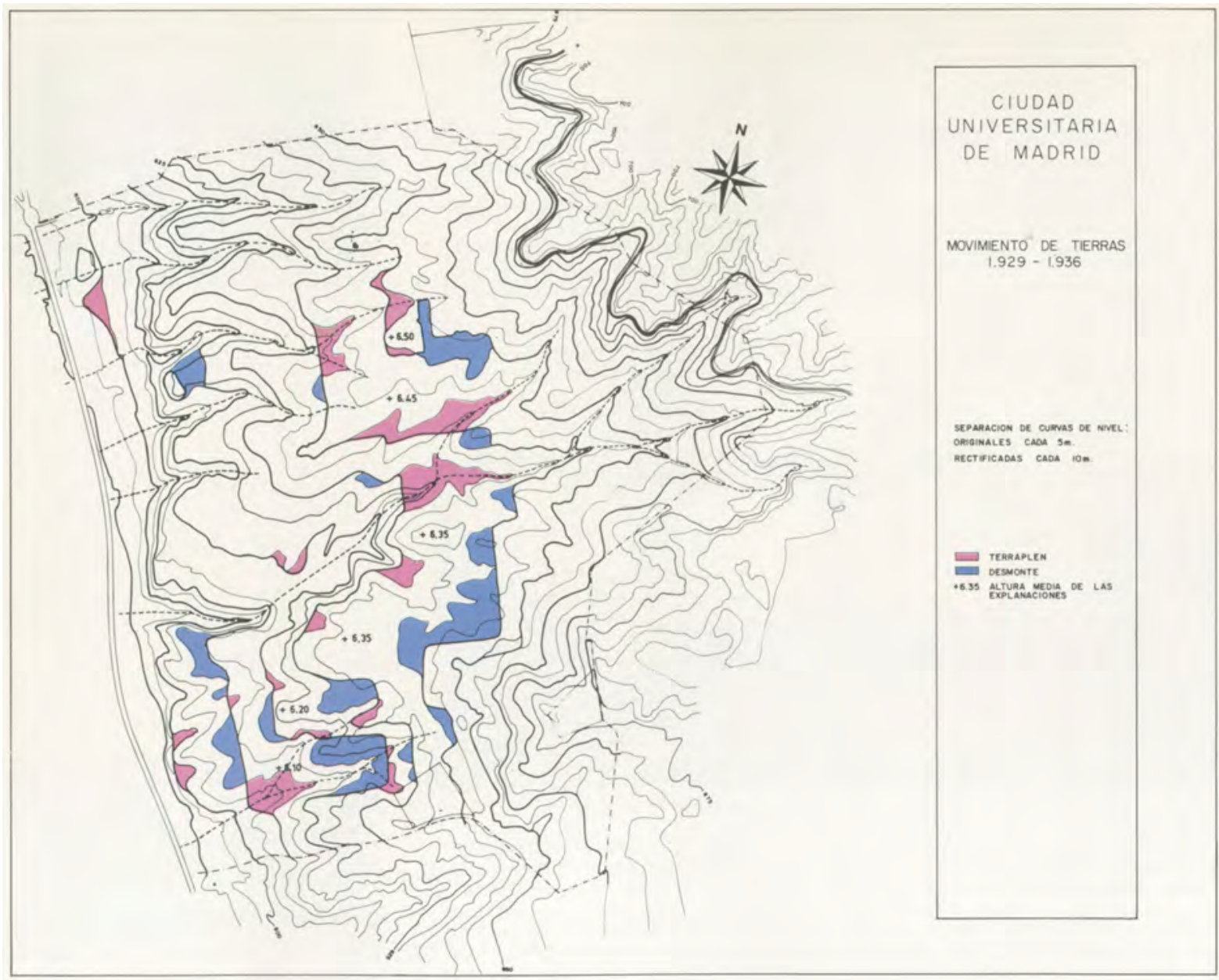

Fig. 9. Pilar Chías: Movimiento de tierras en la Ciudad Universitaria, 1929-1936. (Fuente: Chías, 1986, p. 114).

nuevos usos y masificarse la Universidad. El arquitecto Pérez Mínguez (Conversaciones, 1972) comentó al respecto en 1972:

El llevar la vía de salida de Madrid atravesando la Ciudad Universitaria, yo creo que se hizo intencionadamente, para llevar cierta animación al tráfico, cuando no se preveía el aumento de coches que iban a circular por allí en tan breve plazo de tiempo. Por el contrario, había la preocupación de que la zona quedara desierta. Nótese que en aquella época a la gente le gustaba mucho todo solar que diera a vías importantes, y creo que esa mentalidad fue la que aconsejó dar a esta arteria de la Ciudad Universitaria un sentido de vía secundaria de salida de Madrid, en conexión con la carretera de La Coruña, que entonces ya era el sitio donde probaban sus armas los nuevos propietarios de coches. Yo creo que se dejó este paso intencionadamente para buscar animación de circulación, para crear un espacio que no estuviera vacío de vida ni de circulación. 

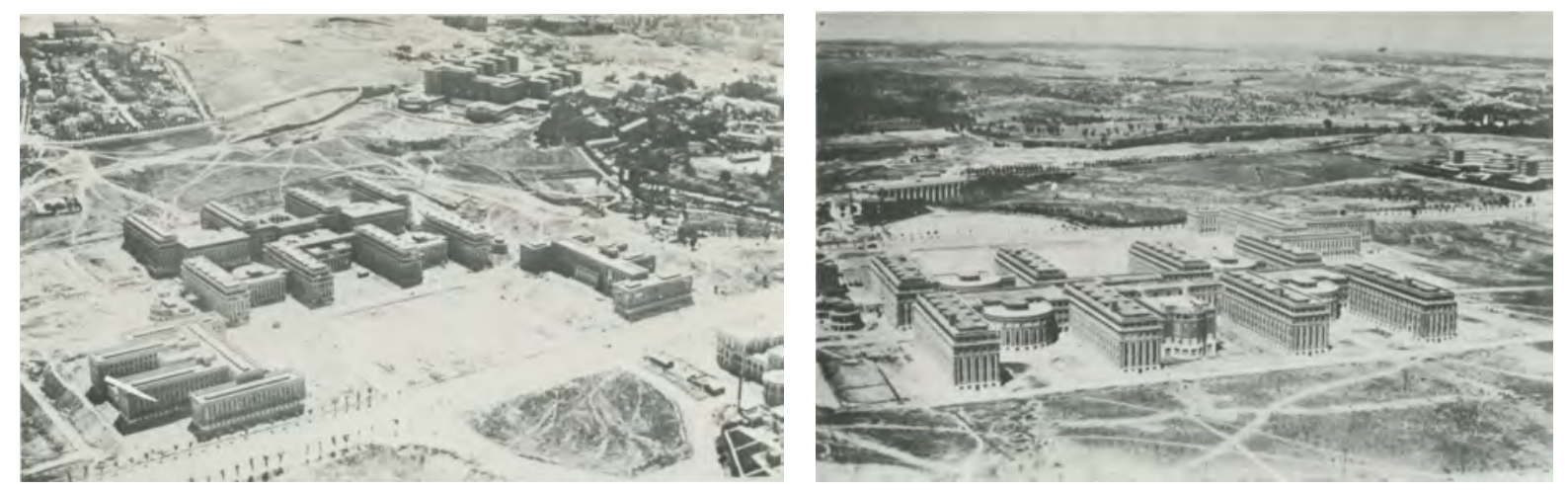

Fig. 10. Vuelo sobre el grupo o campus médico, el Hospital Clínico y el viejo Asilo de Santa Cristina, ca. 1936. (Fuente: Chías, 1986, p. 150).

Pero el campus norteamericano poseía la valiosa cualidad de aglutinar en torno a un recinto más o menos regular la totalidad de la vida estudiantil, incluyendo las residencias, lo que no sólo favorecía los intercambios entre disciplinas sino los sociales, enriqueciendo el ámbito docente. Sin embargo, al aumentar de forma importante la escala del proyecto, la adaptación española perdió de vista las dimensiones reales y, con ello, las posibles ventajas.

En consecuencia, los cuatro grupos o grandes campus adoptaron el aspecto de desproporcionadas plazas simétricas entre edificios de aspecto administrativo, en lugar de convertirse en espacios de relación por carecer del imprescindible equipamiento con la excepción del viario (Fig. 10).

Los espacios exteriores tampoco escaparon a la imposición de los criterios de monumentalidad. Hablando del proyectado Jardín Botánico, López Otero (1950) lo definió como sigue: "Era una remodelación del parque paisaje barroco, que como el marco al palacio real había existido en las capitales de Europa. En realidad, aquí el palacio es el paraninfobiblioteca."

\section{LOS EFECTOS DE LA GUERRA CIVIL: 1936-1939}

A pesar de que en noviembre de 1936 la capital había perdido ya gran parte de su interés estratégico, entre esta facha y el final de la Guerra Civil -el 1 de abril de 1939- el frente se mantuvo más o menos activo en la Ciudad Universitaria, causando graves daños en los nuevos edificios -cuya estructura era de hormigón armado- y la ruina total de los antiguos (Fig. 11).

Según Martínez Bande (1982, p. 223), "los edificios -sobre un paisaje pelado- han acabado aquí convirtiéndose en seres con personalidad”.

La situación de las tropas de ambos bandos quedó cristalizada entre noviembre y el final de la contienda del modo siguiente: las tropas rebeldes o nacionales ocuparon una bolsa en la Ciudad Universitaria que se conectaba con la vecina Casa de Campo a través de la Pasarela de la Muerte, situada pocos metros aguas arriba del Puente de los Franceses. Se 


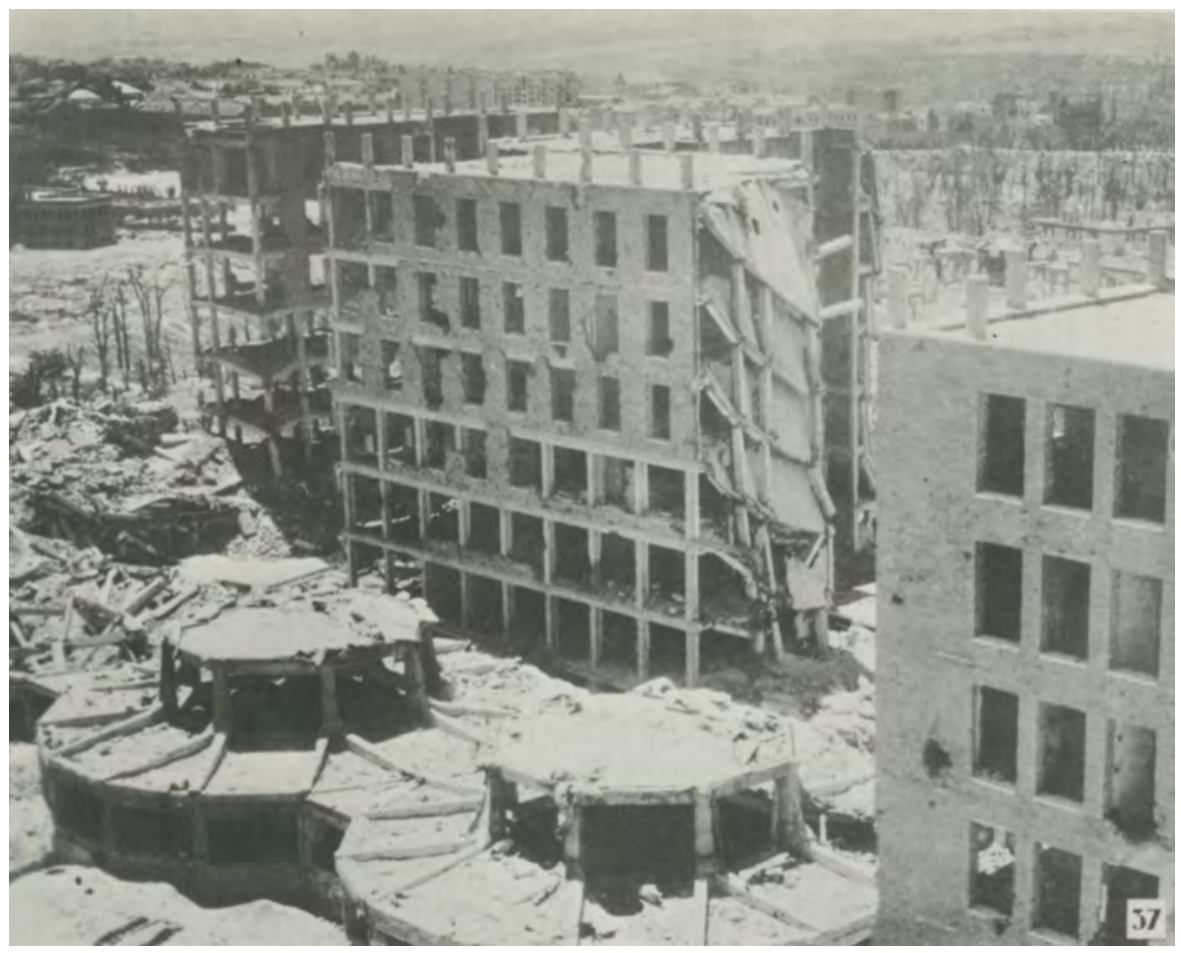

Fig. 11. Daños en la estructura de hormigón del Hospital Clínico debidos a los efectos de las minas. (Fuente: Chías, 1986, p. 156).

situaron en los edificios -o en lo que quedaba de ellos- del Clínico, el Asilo de Santa Cristina, el Instituto de Higiene, la zona de residencias, las Escuelas de Agrónomos y Arquitectura, la Casa de Velázquez y el Palacete de La Moncloa.

En el resto de los edificios y en el Parque del Oeste se situaron las fuerzas republicanas, al otro lado de la calle, frente a las residencias y a escasos $50 \mathrm{~m}$ del enemigo (Fig. 12).

Al final de la Guerra Civil el balance fue desastroso. Edificios desaparecidos, otros gravemente dañados. Y la peor parte la asumieron aquellos que habían sido inaugurados antes de la guerra como la Facultad de Filosofía, o los que estaban a punto de hacerlo en julio de 1936 -como la Escuela de Arquitectura-, ya que los materiales que ya almacenaban -bibliotecas históricas, material de laboratorio, mobiliario, acabados, etc.- sufrieron pérdidas irreparables.

Desaparecieron las delicadas instalaciones, arrancadas con el consiguiente vandálico destrozo, para los fines y empleos más absurdos. Las maderas, así como el corcho de aislamiento, se emplearon como combustible destruyéndose para tal fin costosos revestimientos; los libros y mesas de laboratorio se utilizaron para inútiles parapetos: aparatos sanitarios y mobiliario fueron a parar a lejanos hospitales, oficinas y habitaciones oficiales [...] Cuando en 1939 a la liberación de Madrid se hizo balance de tanta destrucción, pudo comprobarse que fue mucho mayor el daño de la acción personal y directa del hombre que el estrago de las armas bélicas [...] (Chías, 1986, p. 163). 


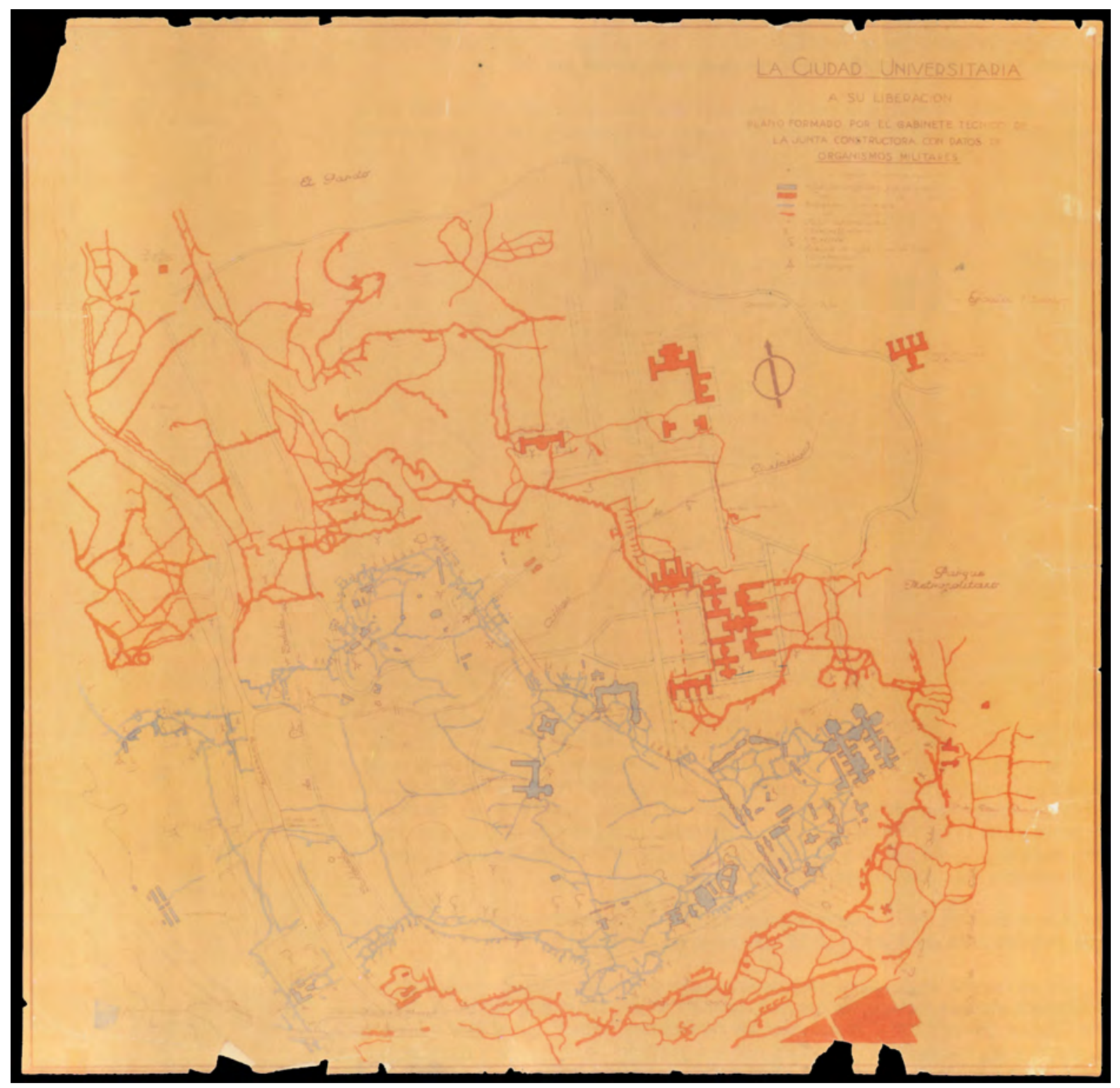

Fig. 12. La Ciudad Universitaria a su liberación. Plano de las trincheras: en azul, las posiciones que ocupaba el ejército rebelde; en rojo, las del ejército republicano. (Fuente: Chías, 1986, p. 162).

Las redes exteriores de abastecimiento y evacuación quedaron muy dañadas por los efectos explosivos subterráneos. Las instalaciones internas y revestimientos de goma, vitrolite, azulejos, metales, etc. no existían ya. Pero las estructuras y fábricas resistieron heroicamente, apareciendo sometidas a esfuerzos sorprendentes y a acciones mecánicas incomprensibles, con situaciones de equilibrio que no podían explicarse: soportes aislados, rota su solidaridad, sometidos a cargas varias veces mayores que las previstas; carreras y grandes vigas, perdidas su cualidad y naturaleza, aguantando pesos extraordinarios sólo con débil flexión; témpanos inmensos con insignificante apoyo, 
lanzados al vacío; muros de extraña verticalidad, sometidos a grandes empujes. (López Otero, cit. en Chías (vid.), pp. 163, 167 y 169).

\section{RECONSTRUCCIONES EN LA POSGUERRA}

Ante el desolador panorama posbélico, los instauradores del nuevo orden dictatorial sintieron la tentación de mantener las ruinas "como un símbolo de memoria eterna de un régimen que nacía y se constituía en cruzada”. Como acertadamente dijo Bonet Correa (1981, p. 11):

el morbo arqueológico de estas ruinas tenía mucho que ver con el intento de fijación de una temporalidad bélica que negaba el futuro como realidad, y se complacía en la proyección del pasado sobre el presente. Las ruinas venían a convertirse, de esta suerte, en poema permanentizado de violencia.

Afortunadamente, el régimen franquista no cedió ante el encanto de las ruinas, ni ante la propuesta de una vuelta de la Universidad a Alcalá para alejar a la siempre conflictiva masa estudiantil de la capital; de modo que transcurridos unos meses se acordó su reconstrucción.

El 10 de febrero de 1940 se creó la nueva Junta Constructora de la Ciudad Universitaria, esta vez presidida por Franco, pero integrando algunas caras conocidas como Modesto López Otero, que estaba de nuevo al frente de la reorganizada Oficina Técnica.

Se optó entonces por redactar un plan de reconstrucción urgente para poner en funcionamiento las facultades y las residencias "con criterios de austera eficacia”, a la vez que, una vez revisados los proyectos precedentes, se acometía la redacción de un nuevo plan acorde a las circunstancias y al ideario político (Fig. 13).

El nuevo concepto de Universidad que definió la Ley de Ordenación Universitaria de 29 de junio de 1943 se incorporó al diseño del reconstruido campus, aportando esencialmente unos criterios continuistas, pero con una mayor presencia activa de la Iglesia Católica y de los símbolos y la ideología conservadora de los militares vencedores.

La nueva Universidad española, que con esta organización puede responder a los poderosos principios inspiradores: Dios y la patria. Universidad católica, porque sin servir a la Patria como poderoso instrumento educador de sus hijos, su misión se falsea y se convierte en centro subversivo del que brotan, en lo ideológico y en lo moral, nefastas aberraciones del espíritu [...] (Franco, 1943).

En ella, el Estado reconocía los derechos docentes de la Iglesia en materia universitaria, cuya presencia activa se hizo patente a través de símbolos y de la propuesta de construcción de templos y de capillas en todos los centros. 


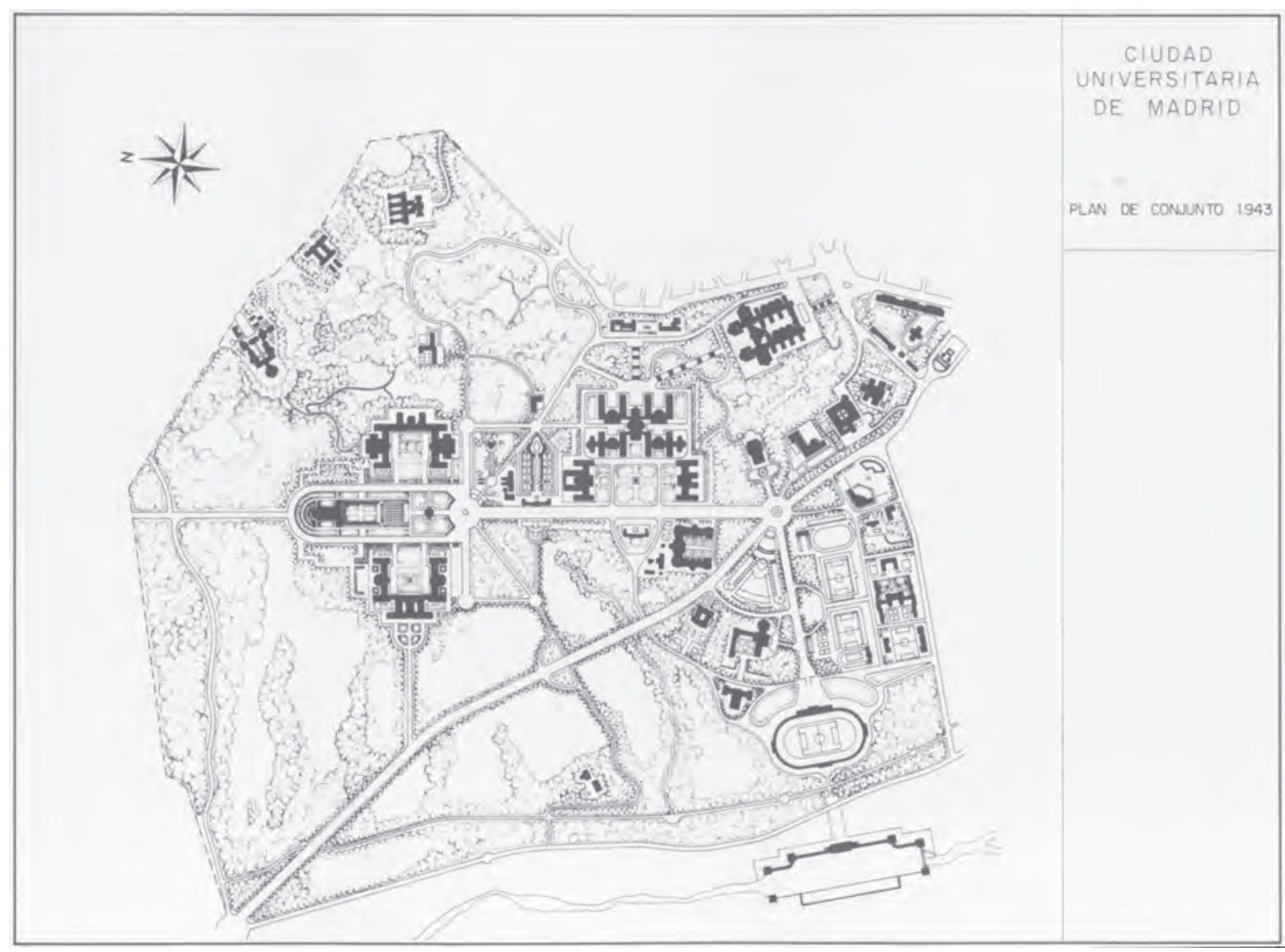

Fig. 13. Pilar Chías, 1986: el nuevo Plan de conjunto de 1943. (Fuente: Chías, 1986, p. 176).

Pero según la ley, la nueva Universidad también debía ajustar "sus enseñanzas y tareas educativas a los puntos programáticos del Movimiento Nacional, y de acuerdo con ellos prescribe la educación física y política de la juventud".

Una de las consecuencias inmediatas fue que las residencias adoptaron el concepto tradicional de colegio mayor, cuyo carácter educador integral iba a garantizar "a la Patria la unidad espiritual de los españoles del futuro".

También se integraron los símbolos de la dictadura en el recinto de forma estratégica, construyendo un itinerario didáctico que incluyó la construcción en lugares destacados de elementos simbólicos como el Arco de la Victoria -en La Moncloa, al inicio de la carretera de La Coruña (Fig. 14)- o el Colegio Mayor José Antonio -en memoria del fundador de la Falange.

Finalmente y en pleno aislamiento internacional, el nuevo régimen también recuperó el viejo guiño al espíritu panhispánico de los gobiernos anteriores a la Guerra, en este caso con construcciones como el Museo de América o colegios mayores patrocinados por diversos países como la Casa del Brasil.

Una vez finalizado el desescombro se optó por no reconstruir las instalaciones aniquiladas por la Guerra, a la vez que se dotó de accesos independientes a las que ocupaban 


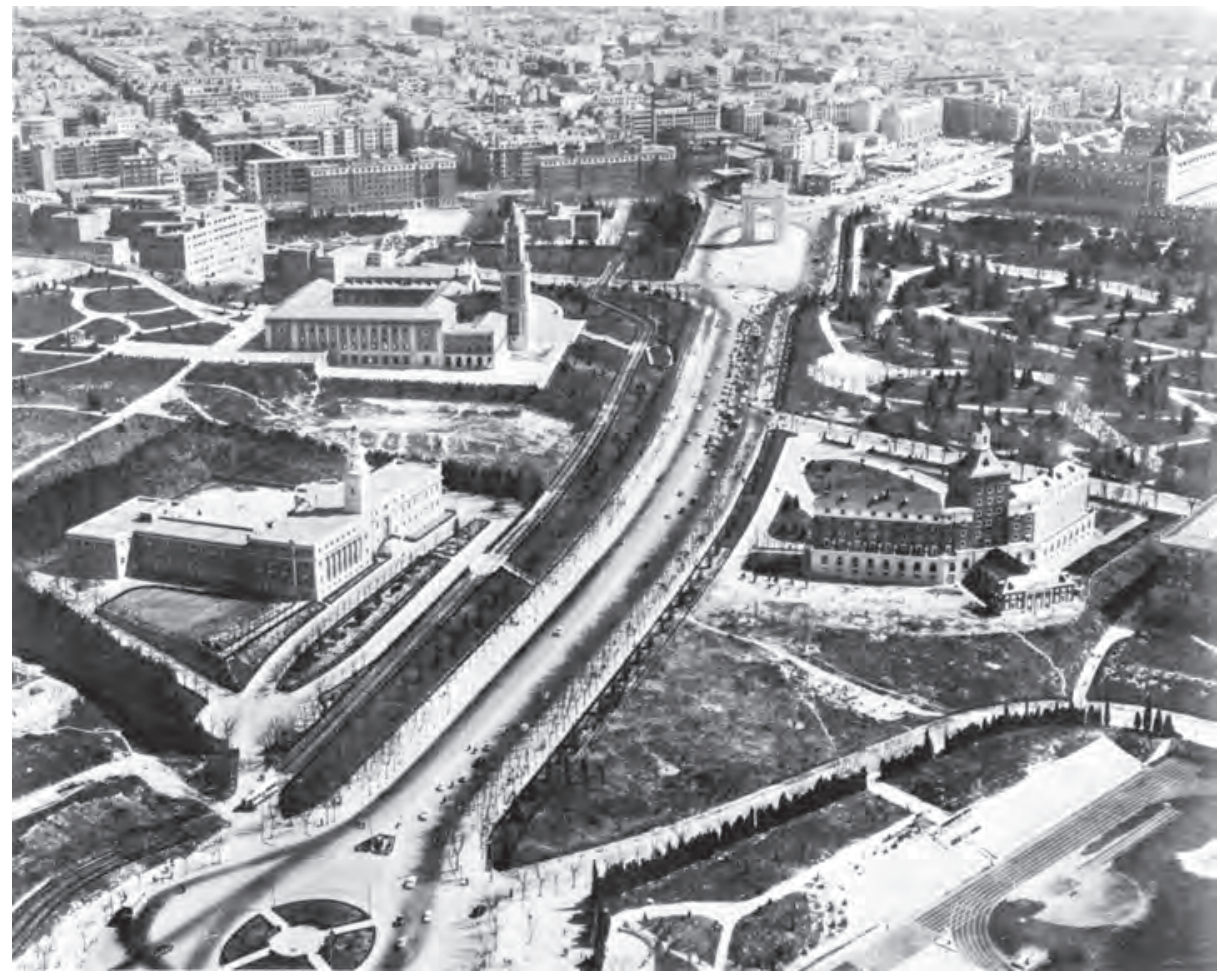

Fig. 14. Vista del Arco de la Victoria y del Museo de América -a la izquierda de la imagen, próximo al Arco- en los años 50. Inicio del itinerario didáctico planteado por la dictadura para difundir su ideario. (Fuente: Chías, 1986, p. 202).

los bordes de la finca, evitando así molestas intrusiones o cruces de circulaciones indeseados.

Tampoco quedó nada de los cuarenta mil árboles de diversas especies que se habían plantado en la etapa anterior, ni de los jardines o las explotaciones agropecuarias del Instituto Agronómico. La repoblación también fue acometida paulatinamente porque la Universitaria se había convertido en "un vasto solar convertido en erial por el azote de la guerra" (Ibáñez Martín, 1950, p. 24) (Fig. 15).

Las primeras inauguraciones, mezcla de "arte ceremonial y liturgia de masas", se sucedieron en 1943 y 1945 y se apoyaron en monumentales arquitecturas efímeras (Fig. 16).

$\mathrm{Al}$ igual que en el barroco, estas máquinas provisionales, realizadas con materiales baratos y humildes, de sencilla ejecución y rápido montaje tenían, entre otras ventajas, la de ser móviles y fácilmente transportables [...] por medio de figuras y arquitecturas tridimensionales, verdaderas escenas emblemáticas por medio de las cuales se adoctrinaba o mostraba al público los signos y dogmas del nuevo orden (Bonet Correa, 1981, p. 19).

Finalmente, la ideología nacionalsindicalista que presidía las reconstrucciones urbanas por todo el país, apareció en el muestrario arquitectónico de la Ciudad Universitaria cuyos 


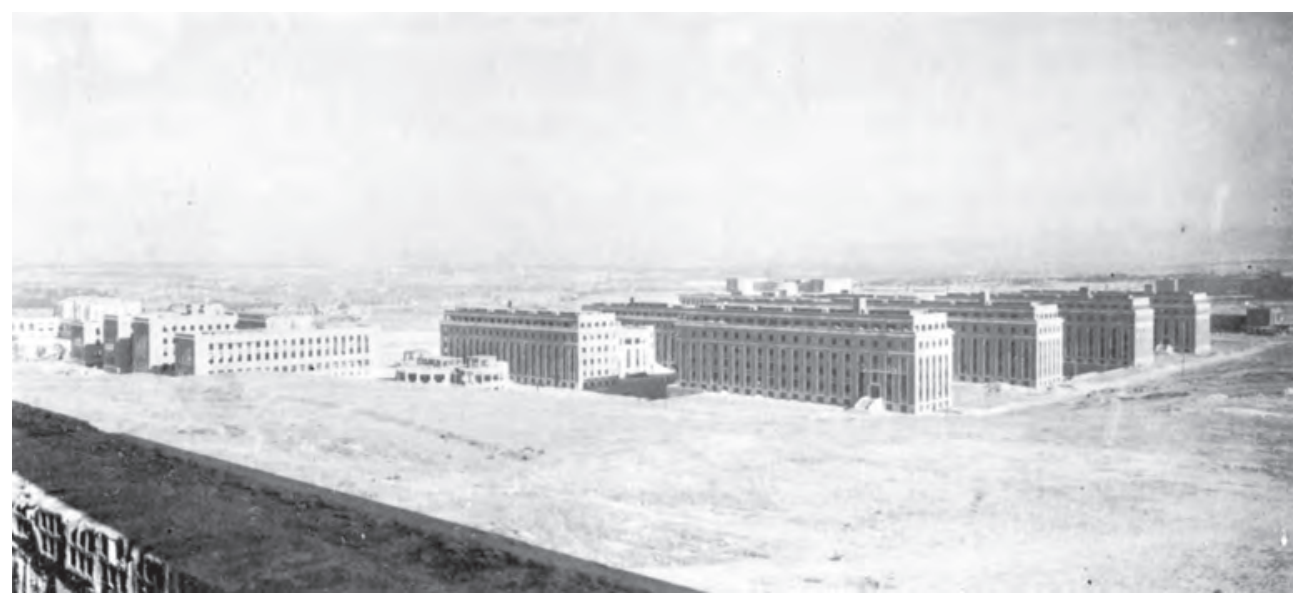

Fig. 15. Vista del campus médico desde el Hospital Clínico a principios de los años 40. (Fuente: Chías, 1986, p. 172).

orígenes estaban en los regímenes políticos anteriores.

Una "versión apócrifa, desde luego heterodoxa, del movimiento moderno" (SoláMorales, 1980, p. 69).

\section{CONCLUSIONES:}

\section{EL CAMPUS DE AGRAMANTE}

El último plan de conjunto que precedió a la reciente redacción del Plan Especial de Reforma Interior (PERI) entre 1980 y 1990, se redactó en 1948. Fue un plan abierto a los imprevistos, con el que se perdió la última posibilidad de ordenación del conjunto según criterios unitarios, ya que siguieron años en los que la Ciudad Universitaria pasó a convertirse en el lugar próximo a Madrid en el que había parcelas disponibles para albergar una gran variedad de usos extrauniversitarios.

En primer lugar, la Junta de Obras ya

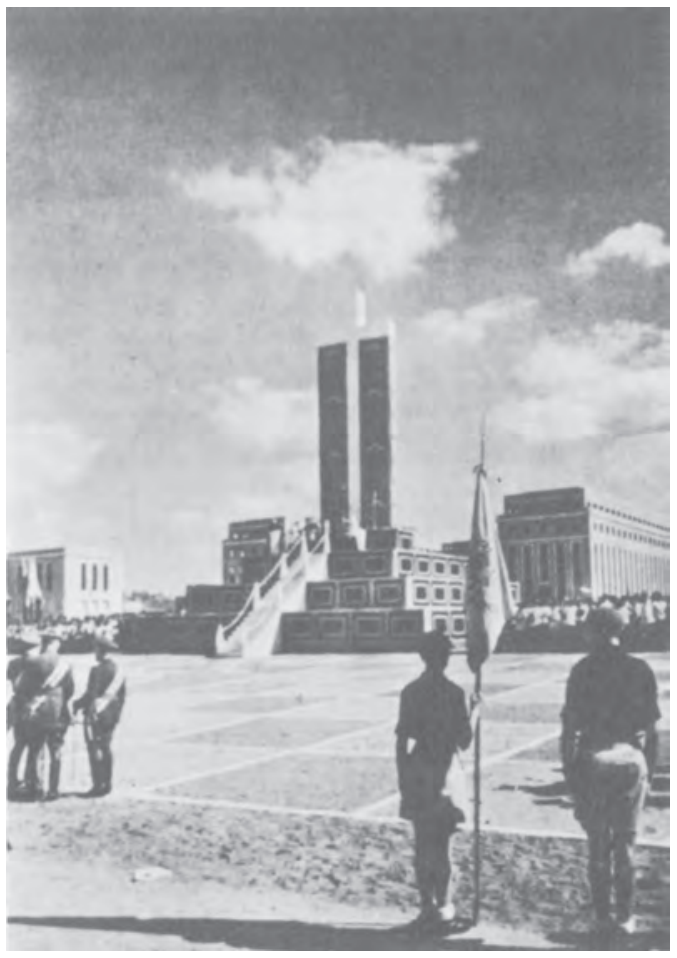

Fig. 16. Arquitecturas efímeras en la celebración del 12 de octubre de 1943 ante la Facultad de Medicina de la Ciudad Universitaria. (Fuente: Chías, 1986, p. 175). no podía actuar de manera totalmente independiente -por ejemplo, para proponer el diseño del viario- pues la Jefatura de Obras Públicas de Madrid ya tenía competencias sobre gran parte de él.

Asimismo, la Jefatura de Urbanismo del Ayuntamiento empezó a intervenir en el diseño 
de los espacios públicos y del perfil de las calles, mientras el Plan de Ordenación de Madrid de 1946 asignaba el carácter de acceso prioritario a Madrid a la Avenida de Puerta de Hierro.

Fue, por tanto, el inicio de un proceso irreversible, una última propuesta escéptica realizada por un equipo que ya era consciente de que no controlaba la situación, y de que el conjunto universitario iba a perder su coherencia a ojos vistas.

Desde el punto de vista urbanístico, un nuevo criterio pasó a regir la planificación urbana de la Universitaria: el del individualismo de cada entidad ocupante y de las actuaciones tan pasajeras como los políticos que las animaron. Al respecto reflexionaba Luis Moya:

no me explico lo que ha ocurrido después de la guerra en la adjudicación de terrenos para construir toda clase de edificios, sin tener en cuenta ninguna de las condiciones establecidas por el plan de López Otero, que, efectivamente, era ordenadísimo [...] Ahora, en cambio, donde cabe un edificio, en un sitio cualquiera, ahí lo meten, venga o no venga a cuento. Da lo mismo mezclar unas escuelas con otras, unas enseñanzas con otras, y todo ello acontece en medio de la más absoluta confusión. (Conversaciones, 1972).

Hoy han quedado lejos estos tiempos del desorden, cuando el vehículo privado lo invadía todo y las aulas estaban masificadas. Cuando ni el conjunto ni los edificios estaban protegidos frente a cualquier reforma o ampliación realizadas sin criterio. Afortunadamente desde 1999 goza de la debida protección al ser considerado Bien de Interés Cultural con la categoría de Conjunto Histórico.

El metro ha llegado al corazón de la Ciudad Universitaria, y con él la regulación del tráfico y del aparcamiento. En el recinto se han instalado sucursales bancarias, terrazas y otros usos, gracias a los cuales la universitaria ya no queda como una "ciudad muerta" al anochecer.

Sin embargo, lo que para el urbanismo resultó ser un campus de Agramante (Chías, 1981), para la arquitectura universitaria supuso un beneficio, pues muchos de los nuevos edificios y proyectos que se fueron incorporando al recinto tenían un gran interés.

Arquitectos tan relevantes como López de Asiaín, Asís Cabrero, Vázquez Molezún, de la Mata, Blanco Soler, Fisac, Higueras o Miró, propusieron edificios que aún hoy siguen siendo referentes de la arquitectura española del último tercio del siglo XX (Figs. 17 a 19).

Por otra parte, la democracia ha favorecido el acceso universal a la educación superior. A la vez se ha relativizado notablemente la presencia de la Iglesia en la universidad, desapareciendo totalmente de la vida cotidiana universitaria, y manteniendo una reducida representatividad a nivel institucional.

Tampoco se mantiene como un reducto de ideologías, pues desde los últimos años del dictador y tras su fallecimiento, las sucesivas generaciones se han mostrado mucho menos activas, hasta el punto de que hoy es difícil encontrar muestras de actividad política o de sus símbolos asociados.

Hoy la Ciudad Universitaria es un conjunto moderno y democrático que se encuentra 
LA CIUDAD UNIVERSITARIA DE MADRID Y LAS IDEOLOGÍAS POLÍTICAS

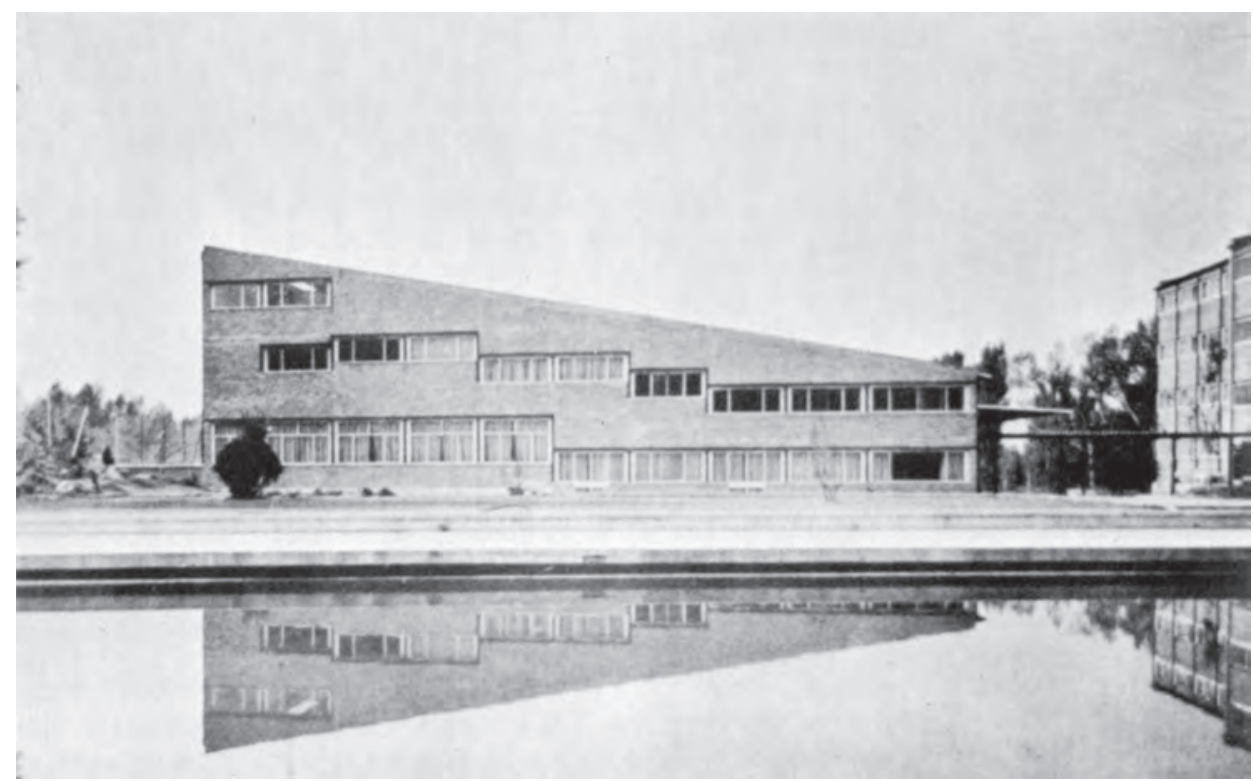

Fig. 17. Francisco de Asís Cabrero, 1960: Colegio mayor San Agustín.

(Fuente: Chías, 1986, p. 228)

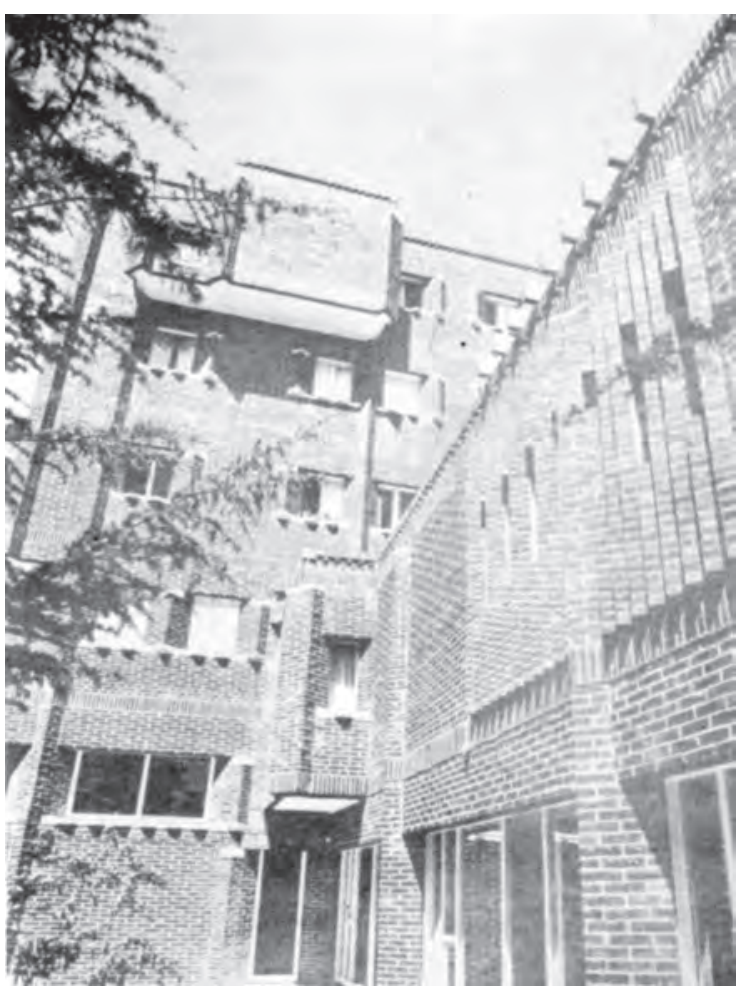

Fig. 18. Ramón Vázquez Molezún y José de la Mata, 1969: Colegio mayor Santa María del Espíritu Santo. (Fuente: Chías, 1986, p. 229).
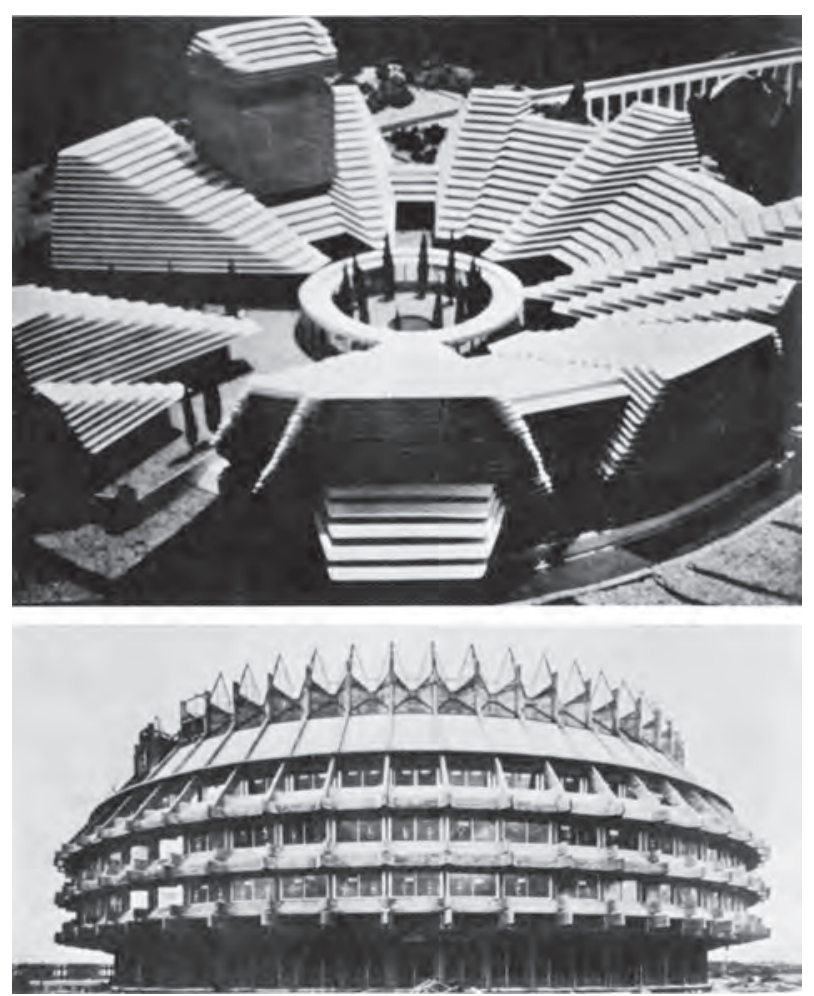

Fig. 19. Fernando Higueras y Antonio Miró, 1970: Instituto de Reproducciones Artísticas. Basado en un proyecto de 1961 de Rafael Moneo y Fernando Higueras. (Fuente: Chías, 1986, p. 234). 
a la vanguardia mundial desde el punto de vista educativo e investigador, y está plenamente integrada en la vida de Madrid, tal y como es contemplada por el planeamiento urbanístico. Y aunque una lectura atenta del conjunto aún revela las huellas de ideologías y decisiones pretéritas, muchos de los errores se han difuminado.

Asumimos, por tanto, las palabras de Fernando Ramón (1981), pues "una ciudad no admite enclaves, ni cities, ni vaticanos, ni ciudades universitarias”.

\section{REFERENCIAS}

Bohigas, O. (1973). Arquitectura española de la Segunda República. Barcelona: Ed. Tusquets. Bonet Correa, A. (1981). Espacios arquitectónicos para un nuevo orden. En A. Bonet Correa (Coord.), Arte del franquismo (pp. 11-46). Madrid: Ed. Cátedra.

Castillo Oreja, M. A. (1982). Alcalá de Henares, ciudad de la Reforma. En A. Bonet Correa (Coord.), Actas del II Simposio de Urbanismo e Historia Urbana en el mundo hispano. Madrid: Ed. Universidad Complutense.

Chías, P. (1981). Campus de Agramante. Revista CAU, 64, 42-47.

Chías, P. (1986). La Ciudad Universitaria de Madrid, génesis y realización. Madrid: Ed. Universidad Complutense.

Chías, P. (2017). Complejidad y contradicción en el urbanismo de Fernando García Mercadal.

En F. García Mercadal (1896-1985), Arquitecto y Académico, Revista Academia, Anexo II, 9-24.

Chías, P., \& Abad, T. (2005). Eduardo Torroja. Obras y proyectos. Madrid: Instituto de Ciencias de la Construcción Eduardo Torroja, CSIC.

Conversaciones sobre la Ciudad Universitaria. Arquitectura, 162-163, julio-agosto de 1972.

El Concurso del Instituto de Física y Química en Madrid. Revista Obras, 7, abril de 1932.

Franco, F. (1943). Discurso pronunciado con motivo de la inauguración de la Ciudad Universitaria, el 12 de octubre de 1943. Disponible en: http://www.filosofia.org/hem/ dep/lne/1943q13a.htm\#franco (Consultado el 5 de noviembre de 2017).

Hegemann, W. (1925). Amerikanische Architektur und Stadtbaukunst. Berlin: Wasmuth Verlag. Ibáñez Martín, J. (1950). Diez años de servicios a la cultura española, 1939-1949. Madrid: Ed. Magisterio Español.

Junta de Obras de la Ciudad Universitaria (1930). La Ciudad Universitaria de Madrid (folleto). López Otero, M. (1927). Entrevista en el Diario ABC, 15 de noviembre de 1927.

López Otero, M. (1941). La arquitectura de la Ciudad Universitaria de Madrid. Revista Nacional de Educación, 4, abril de 1941.

López Otero, M. (1943). La Ciudad Universitaria de Madrid, notas inéditas. En Chías (vid.) p. 163.

López Otero, M. 1950, La Ciudad Universitaria y la arquitectura biotécnica, notas inéditas. En Chías (vid.) p. 95. 
López Otero, M. (1959). Alfonso XIII, Santander y la Ciudad Universitaria, Conferencia inédita pronunciada en la Delegación de Santander del Colegio Oficial de Arquitectos el 22 de abril de 1959. En Chías (vid.), p. 41.

Luque, J. de (1931). Ciudad Universitaria de Madrid: notas críticas. Madrid: Imprenta Góngora. Martínez Bande, J.M. (1982). La marcha sobre Madrid. Madrid: Servicio Histórico Militar. Ramón, F. (1981). Disidencias. Revista CAU, 64.

Solá Morales, I. (1980). Eclecticismo y vanguardia. Barcelona: Ed. Gustavo Gili.

Tusell, J., \& Queipo de Llano, G. (2001). Alfonso XIII, el rey polémico. Madrid: Ed. Taurus.

Winthuysen, X. de (1930). Jardines clásicos de España. Madrid: Compañía Iberoamericana de Ediciones. 